\title{
3D printing of high performance polymer- bonded PEEK-NdFeB magnetic composite materials
}

\author{
L. Pigliaru ${ }^{1,2}$, M. Rinaldi ${ }^{2,3^{*}}$, L. Ciccacci ${ }^{3}$, A. Norman $^{1}$, T. Rohr $^{1}$, T. Ghidini ${ }^{1}$ and F. Nanni ${ }^{2,3}$
}

\begin{abstract}
Permanent Rare Earth magnets are becoming more and more important in efficient motors and generators with high energy density. Among them NdFeB magnets are the most employed, with NdFeB having higher remanence, high coercivity and energy product. Nevertheless, their poor corrosion resistance makes them susceptible to degradation of the magnetic properties. One possible solution is the development of innovative polymeric composite magnetic materials. The preparation of NdFeB powders filled polymeric matrix (PEEK), with a double goal of protecting the magnetic alloy is proposed, thus preventing it from corrosion, and to realize a new material that can be shaped in the form of filaments. This material was used as feedstock in the 3D printing process to produce high performance magnets with customized and optimized design. The PEEK-NdFeB filaments were produced with three percentages of filler amount(i.e. 25, 50 and 75 wt\%). PEEK neat filaments were produced as reference. The influence of the filler on the main thermomechanical properties of the resulting composites, as well as its effect onthe 3D printing process were evaluated by means of different investigation techniques (DSC, DMTA, XRD, tensile testing). The magnetic properties exhibited by Fused Filament Fabrication (FFF) printed parts confirmed the feasibility of employing such a combination of an innovative manufacturing technique and high-performance PEEK-NdFeB compounds.

The characterization carried out on both neat and composite filaments evidenced that the presence of the filler slightly decreased the thermal stability, increased the elastic modulus while decreasing ductility and maximum tensile strength. By means of DSC analysis, it was confirmed that the crystallinity is influenced by the presence of the filler. Magnetic measurement performed on the 3D printed parts demonstrate that interesting magnetic properties were achieved, confirming the feasibility of the magnetic 3D printed composite with PEEK.
\end{abstract}

Keywords: Material extrusion, Fused deposition modeling, Magnetic composite, PEEK composite, NdFeB magnet

\footnotetext{
* Correspondence: marianna.rinaldi@uniroma2.it

${ }^{2}$ Italian Interuniversity Consortium on Materials Science and Technology

(INSTM), Research Unit Roma Tor Vergata, Via della Ricerca Scientifica, 00133

Rome, Italy

${ }^{3}$ Department of Enterprise Engineering, University of Rome Tor Vergata, Via

del Politecnico, 00133 Rome, Italy

Full list of author information is available at the end of the article
}

\section{Springer Open}

(c) The Author(s). 2020 Open Access This article is licensed under a Creative Commons Attribution 4.0 International License, which permits use, sharing, adaptation, distribution and reproduction in any medium or format, as long as you give appropriate credit to the original author(s) and the source, provide a link to the Creative Commons licence, and indicate if changes were made. The images or other third party material in this article are included in the article's Creative Commons licence, unless indicated otherwise in a credit line to the material. If material is not included in the article's Creative Commons licence and your intended use is not permitted by statutory regulation or exceeds the permitted use, you will need to obtain permission directly from the copyright holder. To view a copy of this licence, visit http://creativecommons.org/licenses/by/4.0/. 


\section{Introduction}

Rare-earth based Nd-Fe-B permanent magnets have consistently gained a large commercial importance for applications where the need of achieving high magnetic performance associated with low volume and weight is a key driver. Permanent magnets (PMs) are currently used in several space mechanism and equipment (e.g. actuators, motors, drive systems and their sensors, control and electronic components). NdFeB magnets are commonly employed in the fully dense sintered form, due to their superior magnetic properties, as they show high $(\mathrm{BH})_{\max }$. On the other hand, sintered $\mathrm{NdFeB}$ are difficult to shape in complicated geometries, due to their brittleness. NdFeB magnets must be machined (with limitations) to their final form as they are not suitable for near net shape processing, with a noticeable waste of material and restriction in the achievable final shapes. Moreover, they exhibit poor corrosion resistance and, therefore, need to be protected. Currently there are different approaches to prevent corrosion issues of PMs, that are based on either the improvement of the intrinsic properties of the bulk material (i.e. modifying the alloy) [1-3], the use of coatings [4-9] to provide environmental shielding, or the use of binders or polymeric matrixes to embed $\mathrm{NdFeB}$ powders [8-10]. In the latter case, both thermosets and thermoplastic polymeric matrices have been proposed in the literature, such as epoxy resin [11-13], polyamide (PA) [14] [15], or polyphenylene sulphide (PPS) [16].

Although polymer bonded magnets are not comparable with sintered magnets in terms of magnetic performance, they can be shaped and miniaturized, thus reducing weight and volume. Anisotropic $\mathrm{NdFeB}$ composite magnets were proven to achieve $\mathrm{BH}_{\max }$ of 17 MGOe, (thus being suitable to replace some sintered magnets) together with low electrical conductivity, which limits eddy current losses and increases their performance [8]. The introduction of additive manufacturing (AM), also known as 3D printing, allows the introduction of thermoplastic magnetic composites via Fused Filament Fabrication (FFF) [17, 18]. This is particularly interesting in view of space programs that look towards long-term missions in deep space, where the practical need for self-sustainability arises [19, 20].

Extrusion-based AM, such as fused filament fabrication (FFF), of magnetic composites has been previously proposed in the literature [15, 21-23] being the natural evolution of the standard extrusion techniques already established for bonded magnets. In order to achieve good magnetic properties of the printed magnet, a high percentage of the magnetic filler is needed, that results in an increased viscosity of the composite filaments, which in turn decreases the printability and accuracy [24-29]. In highly-filled isotropic near-net-shape $\mathrm{NdFeB}$ bonded nylon magnets (65\% vol), which were printed by the Big Area Additive Manufacturing (BAAM) technique [22, 30], a large $3.1 \mathrm{~mm}$ nozzle was used in order to overcome the poor flowability of the highly filled composite filaments. This large diameter nozzle (nearly 8 times larger than a standard $0.4 \mathrm{~mm}$ FFF nozzle) does ensure printability, but also limits the use of this technique to low accuracy and part resolution, due to the intrinsic impossibility of rendering small features and tolerances.

In research performed by $\mathrm{Li}$ at al [31]., PA12 + 70 vol\% NdFeB was printed using a nozzle of $7.6 \mathrm{~mm}$ in diameter. As expected, the resulting part possessed higher magnetic properties compared to $65 \mathrm{vol} \%$ BAAMor injection moulding parts. However the PA $12+70$ vol\% NdFeB had lower mechanical properties [22].

Huber et al. [15] demonstrated the use of standard FFF technology to print nylon with spherical NdFeB particles. The printed parts showed no processinduced anisotropy, suggesting that the layer-wise building process does not affect the magnetic orientation of the spherical particles. However, the FFF printed parts showed an average reduction of $20 \%$ of the magnetic remanence compared to samples prepared via injection moulding.

Recently Petersdorff et al. [23] investigated the FFF production of polyoxymethylene (with 7.34\% wt. $\mathrm{NdFeB}$ ) and PA12 (with 24.46\% wt. NdFeB) based magnetic compounds to print a blood rotary pump impeller. A small magnetic remanence was measured, which was attributed mainly to the presence of voids and porosity, whilst intrinsic coercivity showed no dependence on porosity or filler content. On the other hand, the limited flowability of the material that caused the porosity, is also the main factor why a larger nozzle was used, which is the reason for the lower resolution, compared to usual FFF parts. It was

Table 1 Sample type and nomenclature

\begin{tabular}{llll}
\hline Sample & Type & Filler Type & Filler amount (\%wt) \\
\hline PEEK_neat & Filament & - & 0 \\
PEEK_neat_3D & 3D Printed & - & 0 \\
PEEK_25NdFeB & Filament & NdFeB & 25 \\
PEEK_25NdFeB_3D & 3D Printed & NdFeB & 25 \\
PEEK_50NdFeB & Filament & NdFeB & 50 \\
PEEK_50NdFeB_3D & 3D Printed & NdFeB & 50 \\
PEEK_75NdFeB & Filament & NdFeB & 75 \\
\hline
\end{tabular}


also noted by the same research group that poor layer adhesion was observed.

Ethylene-ethyl acrylate (EEA), a transparent thermoplastic copolymer with exceptional low-temperature flexibility and impact resistance, was used as the matrix of 3D printed NdFeB- and SrFeO-based magnets [32]. The results showed good remanence, even though difficulties in the extrusion/printing process were reported.

PEEK was identified as the preferred polymeric candidate being widely used in space applications because of its compliance with the very restrictive requirements such as: high thermal stability, low outgassing, low flammability and high radiation resistance [33-35]. PEEK is a semicrystalline organic polymer thermoplastic in the polyaryletherketone (PAEK) family, used in engineering applications. It exhibits highly stable chemical structure, high mechanical and thermal properties. The Young's modulus is $3.6 \mathrm{GPa}$ and its tensile strength 90 to $100 \mathrm{MPa}$. PEEK has a glass transition temperature of around $143^{\circ} \mathrm{C}$ and melting temperature of $343^{\circ} \mathrm{C}$ and an onset of decomposition temperature between 575 and $580^{\circ} \mathrm{C}$ [36-39], which makes it, one of the most thermally stable thermoplastic polymer, due to the stability of the aromatic backbone comprising the bulk of the monomer unit [40, 41].

Recently PEEK has been used to produce 3D printed parts obtaining mechanical performance similar to that reported for PEEK processed by traditional injection moulding $[42,43]$. In some cases thought the ultimate strength of 3D printed PEEK samples decrease to about half of the traditional injection moulding PEEK and in other cases they showed mechanical properties according to the polymer data sheet value, depending on printing conditions and orientation [39]. In particular, it was pointed out that the thermal conditions seem to be the crucial point in FFF printing of PEEK, as they have a strong influence on crystallinity, residual stresses and, thus, mechanical properties [44].

Despite the fact that promising results have been documented in the literature, none of the intended applications were directed towards space. Most of the polymers used until now are not thought to be compatible with the environment found in space. PA, for instance, has a limited use in the space domain, due to its hygroscopicity that can cause potential cross contamination, due to outgassing [45]. Based on the current state of the art, there is therefore a need for a high-performance thermoplastic-based bonded permanent magnet for space applications [10]. This development is the focus of the work reported in this article.

In this research NdFeB loaded PEEK filaments (at 25, 50 and $70 \%$ wt loading) were produced and FFF printed for the first time. A wide characterization was performed on both filaments and printed parts to assess the resulting properties, in terms of thermal and mechanical performance and in terms of functional magnetic properties.

\section{Materials and methods}

PEEK 450P (Victrex plc, UK) with molecular weight $115.00 \mathrm{~g} / \mathrm{mol}$ was used as polymeric matrix. NdFeB powders (Newland Magnetics Europe, France, Grade ZRK-A) in form of flakes with average thickness of $35 \mu \mathrm{m}$, were used as magnetic filler. In terms of magnetic characteristics, the powder shows remanence $\left(\mathrm{B}_{\mathrm{r}}\right)$ in the range 0.74$0.80 \mathrm{~T}$ and coercivity $\left(\mathrm{H}_{\mathrm{c} j}\right)$ of $440-496 \mathrm{kA} / \mathrm{m}$, after magnetization [46]. The as-received powder was not magnetized, to allow for composite preparation.

A sieve was used to remove particles with size larger than $150 \mu \mathrm{m}$, aiming to reduce the risk of nozzle clogging during the printing.

Matrix and filler were premixed using a planetary mixer (Thinky ARE-250) and successively extruded in $1.75 \pm 0.05 \mathrm{~mm}$ diameter filaments, using a single-screw extruder (FILABOT, USA),screw speed $25 \mathrm{rpm}$ temperature $340^{\circ} \mathrm{C}$. PEEK neat filaments were extruded as well, as reference. All produced filaments were successively 3D printed with an INDMATEC GmbH FFF printer to produce 5 tensile test specimens, according to ASTM D638-TypeV, and 3 cylindrical sample (diameter $\Phi 21 \mathrm{~mm}$, height $5 \mathrm{~mm}$ ). CAD files were imported to SIMPLIFY 3D software (SIMPLIFY 3D, USA), to slice and set the printing parameters.

All specimens were printed horizontally on the building platform, with a raster angle of $+45^{\circ} /-45^{\circ}$ in alternate layers and $100 \%$ infill. Building platform temperature was set at $100^{\circ} \mathrm{C}$ while nozzle temperature was set at $400^{\circ} \mathrm{C}$. Table 1 summarizes all produced filaments and 3D printed samples.

PEEK_neat and PEEK_25NdFeB were printed with nozzle diameter $0.4 \mathrm{~mm}$ while the PEEK_50NdFeB filaments required the use of a nozzle with a larger diameter (i.e. $0.8 \mathrm{~mm}$ ) due to the very high melt viscosity of the composite.

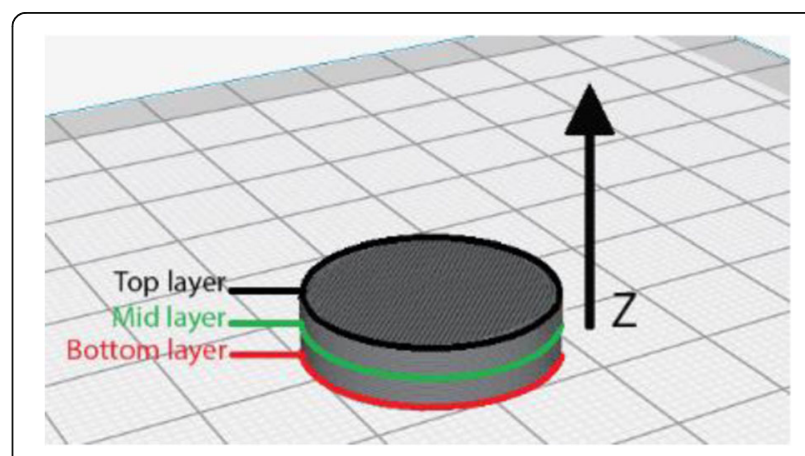

Fig. 1 Layer scheme: red line refers to bottom layer in contact with the building platform, the green line refers to the middle layer at the centre of the sample, the grey line refers to the top surface layer 

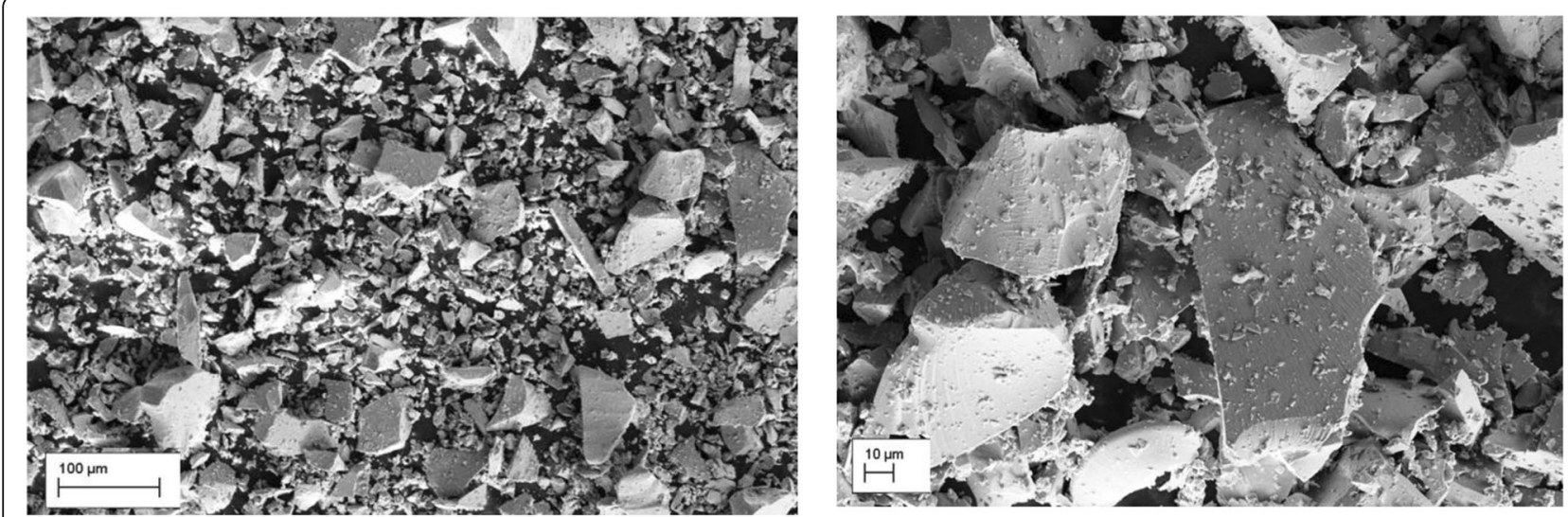

Fig. 2 SEM image of the ZRK-A powders before sieving

$\mathrm{NdFeB}$ powder were characterized prior to use via scanning electron microscope and X-Ray diffraction. SEM inspection was performed with a Zeiss Leo 1530 VP SEM with a Shottky field emission source. EDX analysis was performed with and Oxford instruments Xmax80 silicon drift detector and the analysis software INCA.

X-Ray diffraction (XRD, Philips X'Pert, $\mathrm{Cu} \mathrm{Ka}=$ $1.524,2 \mathrm{~s}$ per step, $0.02^{\circ} \mathrm{scan}$ step size, $2 \theta$ from $5^{\circ}$ to $90^{\circ}$, powder sample holder) in terms of microstructure, chemical composition and phase analysis to exclude the presence of oxides and corrosion products prior to processing.

Melt Flow index tests (MP $1200 \mathrm{M}$ Melt Flow Indexer, Tinius Olsens temperature $\mathrm{T}=400^{\circ} \mathrm{C} ; \mathrm{m}=2,16 \mathrm{~kg}$ ) were performed on all premixed composite powders, as well as on as-purchased peek powder, according to ASTM D1238-13, prior to filament extrusion.

Density measurements of filaments and 3D printed cylindrical samples were performed according to ASTM D792 by means of a pycnometer (Analytical balance Sartorius $\left.^{\mathrm{Tx}}\right)$. Mean density values, coming from at least 3 measurements for each specimen, were compared with theoretical density given by the rule of mixture reported in Eq. 1:

$$
\rho_{\text {comp }}=\% v_{\text {ol }} l_{\text {PEEK }} \rho_{\text {PEEK }}+\% v_{\text {ol }} l_{\text {PEEK }} \rho_{\text {NdFeB }}
$$

Where $\rho_{\text {comp }}, \rho_{\text {PEEK }}$ and $\rho_{\text {NdFeB }}$ are the densities of, respectively, the composite, the neat peek and the magnetic powder as taken from data sheet, while \% vol is

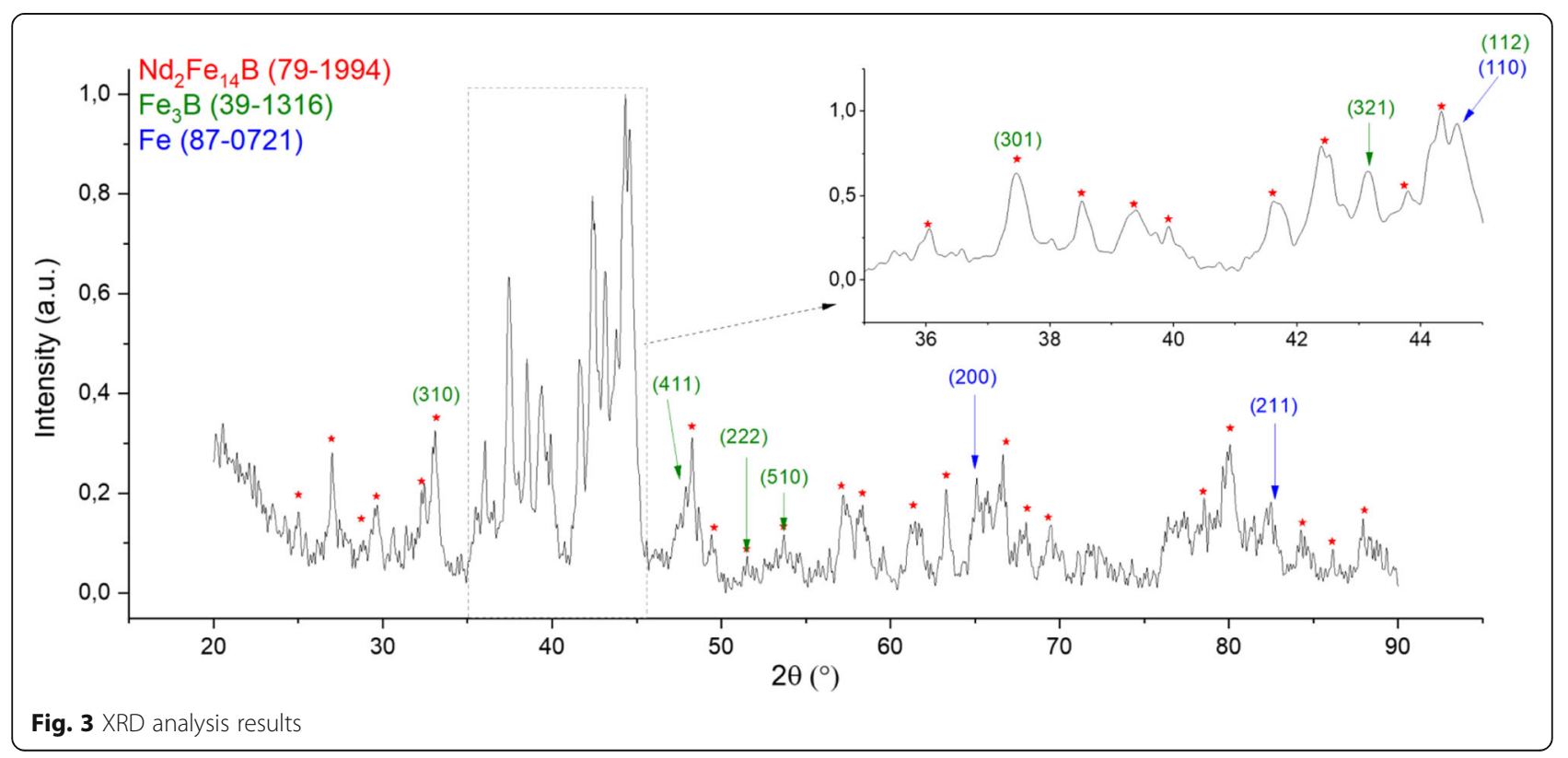


volume fraction. In the case of the presence of voids, porosity was considered as a second filler, and the equation implemented accordingly.

Microsections of a 3D printed cylindrical sample with 50\%NdFeB particles (PEEK_50NdFeB_3D) was performed and inspected with Leica Optical Microscope MEF4M (Leica Microsystems, The Netherlands) microscope to verify the presence of porosity and filler amount in the produced parts. The sample for Magnetic characterization was mounted in resin and grinded manually. Image analysis and porosities calculation were performed with Clemex Vision PE software. A total of 19 images were analyzed and the average values of the porosities calculated.

Thermal analysis on both produced filaments and 3D printed cylindrical samples, was carried out by means of DSC (Mettler Toledo, US) model SDTA/822e, $10 \mathrm{mg}$, temperature range $-50{ }^{\circ} \mathrm{C} /+400^{\circ} \mathrm{C}$, heating scan $10{ }^{\circ} \mathrm{C} /$ min, in nitrogen) to assess the effects, if any, of the 3D Printing process on the physical properties such as thermal stability, degree of crystallinity, melting and crystallization temperature.

The following equation was used to calculate the degree of crystallinity from DSC [47]:

$$
X_{c r}=\frac{\Delta H}{\Delta H^{o}\left(1-w_{f}\right)}
$$

where $\Delta \mathrm{H}_{\mathrm{m}}$ and $\Delta \mathrm{H}_{\mathrm{c}}$ are the enthalpy of fusion at melting point as measured from DSC by the area under the endothermic peak, and the enthalpy of crystallization as measured by the area under the exothermic crystallization peak, respectively. $\Delta \mathrm{H}_{\mathrm{f}}$ is the enthalpy of fusion of fully crystalline PEEK, which was taken equal

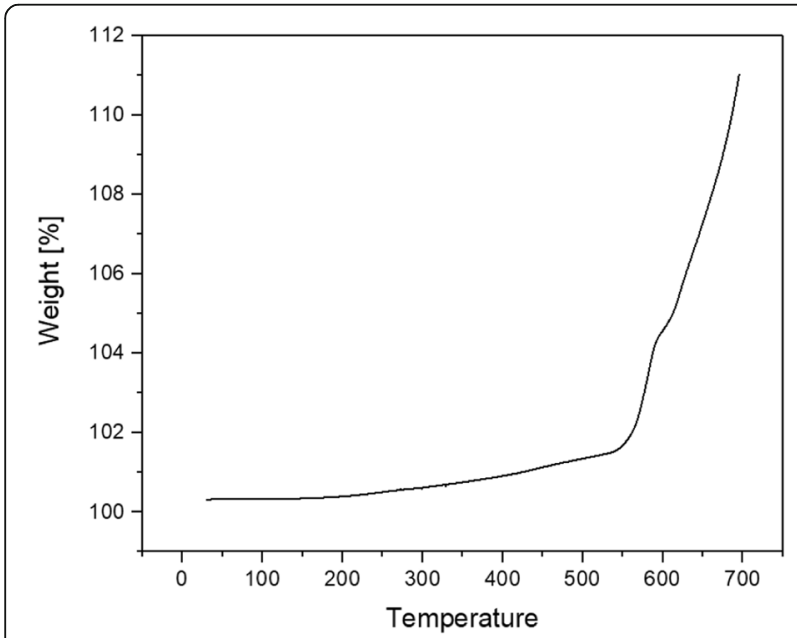

Fig. 4 TGA of $\mathrm{NdFeB}$ powder
Table $2 \mathrm{MFI}$ comparison

\begin{tabular}{lll}
\hline Composition & $\begin{array}{l}\text { MFI (g/10 min) } \\
\text { Mean value }\end{array}$ & Standard Deviation \\
\hline PEEK & 4 & 0.5 \\
PEEK_25NdFeB & 2.0 & 0.2 \\
PEEK_50NdFeB & 1.6 & 0.1 \\
PEEK_75NdFeB & 1.1 & 0.2 \\
\hline
\end{tabular}

to $130 \mathrm{~J} / \mathrm{g}$ [48]; and $\mathrm{w}_{f}$ is the weight percentage of the filler in the compound.

The DSC analysis of 3D printed parts was carried out on three different layers of the samples (bottom, middle and top layer, as sketched in Fig. 1, to assess the quality of the printing process in terms of homogeneity and crystalline structure.

DMA analysis was conducted using a DMA SDTA/ 861e unit, (Mettler Toledo, US). The measurements were performed in tensile mode, temperature range $100{ }^{\circ} \mathrm{C} / 270^{\circ} \mathrm{C}$, cooling and heating rates of $5^{\circ} \mathrm{C} / \mathrm{min}$, frequency $1 \mathrm{~Hz}$, dynamic force $10 \mathrm{~N}$, and displacement amplitude $50 \mu \mathrm{m}$.

TGA was carried out on $\mathrm{NdFeB}$ powder and 3D printed cylindrical samples using a TGA SDTA/851e thermobalance (Mettler Toledo, US). Samples were heated at $5{ }^{\circ} \mathrm{C} / \mathrm{min}$ from ambient temperature to $720^{\circ} \mathrm{C}$, under nitrogen atmospheres, with a gas purge rate of $70 \mathrm{ml} / \mathrm{min}$ in both cases.

Tensile tests of filaments were performed by means of universal testing machine (Lloyd LRX, equipped with $500 \mathrm{~N}$ load cell at $5 \mathrm{~mm} / \mathrm{min}$, up to rupture, 10 specimens were tested for each type of sample). Tensile tests of 3D Printed samples were performed according to ASTM D638-10 (Type V micro-tensile specimens, length $=63.5 \mathrm{~mm}$, width $=9.53 \mathrm{~mm}$ and thickness $=3 \mathrm{~mm}$, with a Zwick/RoellZ100 testing machine, equipped with laser extensometer, at $1 \mathrm{~mm} /$ min. Fracture surface of filaments and 3D printed tensile sample was investigated after gold coating (25 $\mathrm{mA}, 1 \times 10-4$ bar,120 s) by means of scanning electron microscopy to investigate the distribution of the

Table 3 Summary of the main results of DSC analysis on filaments

\begin{tabular}{|c|c|c|c|c|c|c|c|c|}
\hline & \multicolumn{3}{|c|}{ First heating } & \multicolumn{2}{|c|}{ Cooling } & \multicolumn{3}{|c|}{ Second heating } \\
\hline & $\begin{array}{l}\overline{\mathrm{T}_{\mathbf{g}} \mathrm{l}} \\
\left({ }^{\circ} \mathrm{C}\right)\end{array}$ & $\begin{array}{l}X_{m} \mid \\
(\%)\end{array}$ & $\begin{array}{l}T_{m} l \\
\left({ }^{\circ} \mathrm{C}\right)\end{array}$ & $\begin{array}{l}\mathrm{T}_{\mathrm{c}} \\
\left({ }^{\circ} \mathrm{C}\right)\end{array}$ & $\begin{array}{l}X_{c} \\
(\%)\end{array}$ & $\begin{array}{l}\overline{T_{\mathbf{g}} \|} \\
\left({ }^{\circ} \mathrm{C}\right)\end{array}$ & $\begin{array}{l}X_{m} \| \\
(\%)\end{array}$ & $\begin{array}{l}T_{m} \| \\
\left({ }^{\circ} \mathrm{C}\right)\end{array}$ \\
\hline PEEK & 144 & 31.5 & 342 & 298 & 37.2 & 143 & 37.7 & 342 \\
\hline PEEK_25NdFeB & 143 & 31.6 & 342 & 298 & 35.7 & 142 & 35.7 & 342 \\
\hline PEEK_50NdFeB & 143 & 30.8 & 340 & 287 & 34.6 & 141 & 32.5 & 340 \\
\hline PEEK_75NdFeB & 142 & 23.9 & 341 & 281 & 28.8 & 141 & 28.6 & 340 \\
\hline
\end{tabular}



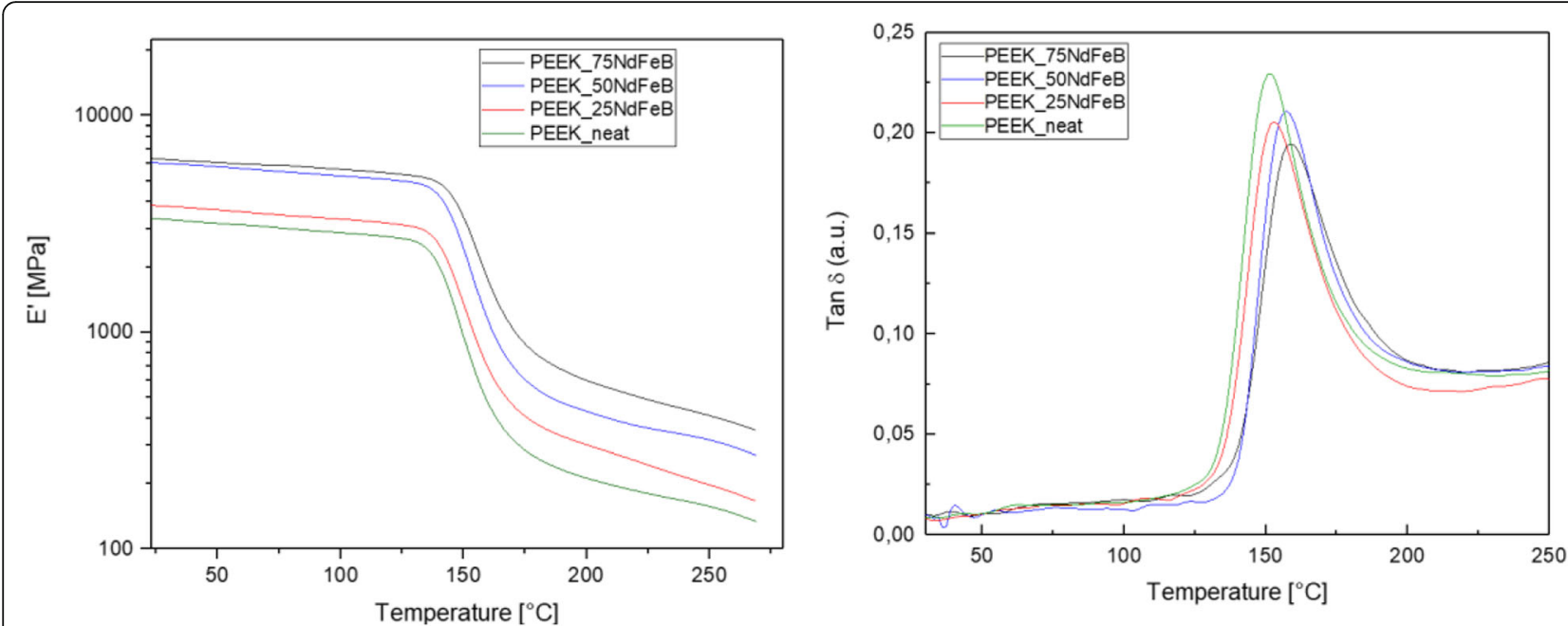

Fig. 5 DMTA results: Storage modulus (left) Tan $\delta$ (right) of PEEK_NdFeB filaments

fillers within the polymeric matrix and the adhesion between filler and matrix.. The analysis was performed with a Zeiss Evo 60 SEM at $20 \mathrm{kV}$ using a nominal working distance of $15 \mathrm{~mm}$ for optimal image quality. The SEM was fitted with an Oxford Instruments XMaxn 80 Silicon Drift Detector. The analysis has been done using Inca Suite V5.0 software.

Magnetic analysis apparatus consisted of an MagMicromag magnetizer and an AMH-500 BH-Tracer hysteresis graph for hard magnets, (LaboratorioElettrofisico, Italy). All 3D Printed samples were first externally magnetized in the MagMicromagat $3000 \mathrm{~V}$, which generates a field of over $3 \mathrm{~T}$ in the air gap within the magnetizing coil.

The hysteresigraph performs closed-circuit measurements in which the material is in the form of a block or cylinder with uniform cross section and parallel faces, and it is clamped between the poles of an electromagnet so that it forms part of the closed magnetic circuit [49]. The field in the electromagnet is swept, and B (or $\mathrm{M}$ ) and $\mathrm{H}$ are recorded on a computer. The measurements were conducted at room temperature on $3 \mathrm{D}$ printed cylinder samples, sweeping the external field $(\mathrm{H})$ from $1000 \mathrm{kA} / \mathrm{m}$ to $-1000 \mathrm{kA} /$ $\mathrm{m}$ and using an LJA-26 coil. Each measure has been

Table 4 PEEK_NdFeB filaments: DMTA results

\begin{tabular}{lll}
\hline & Storage Modulus [GPa] & Max Tan $\delta\left[^{\circ}\right]$ \\
\hline PEEK & $3,3 \pm 0.3$ & $152 \pm 0.8$ \\
PEEK_25NdFeB & $3,8 \pm 0.5$ & $153 \pm 2.0$ \\
PEEK_50NdFeB & $6 \pm 0.4$ & $157 \pm 1.1$ \\
PEEK_75NdFeB & $6,5 \pm 0.5$ & $159 \pm 1.3$ \\
\hline
\end{tabular}

repeated three times for each specimen. At least 3 $3 \mathrm{D}$ printed specimen of each composition were measured.

The value of $\mathrm{Br}$ for the magnetic powder according to the datasheet is $748 \mathrm{mT}$ [46]. The expected $\mathrm{Br}$ values have been calculated based on Eq. and Eq. derived from the results reported by Zhang et al. [50] and Goll et al. [51]. As reported in Eq. 3, Br has a linear dependence to the effective volumetric fraction of the magnet that concurs to the magnetic properties. $(\mathrm{BH})_{\max }$, in turn, has a quadratic behavior with $\mathrm{Br}$ (and with the particles content) according to Eq. 4. The estimation of void content was also necessary in order to calculate the expected Br.

$$
\begin{aligned}
& B_{r}=v_{f}\left(1-v_{\text {void }}\right) B_{r, \text { powder }} \\
& (B H)_{\text {max }, \text { bonded }} \propto\left[v_{f}\left(1-v_{\text {void }}\right) B_{r, p o w d e r}\right]^{2}
\end{aligned}
$$

\section{Results and discussion}

Raw materials characterization

As received NdFEB powders were analysed with SEM/ EDX (Fig. 2) and XRD (Fig. 3). SEM images show the

Table 5 Summary of the main results of TGA analysis on filaments in nitrogen

\begin{tabular}{llll}
\hline & $\begin{array}{l}\text { Temperature 2\% } \\
\text { mass loss }\left({ }^{\circ} \mathrm{C}\right) \\
\text { Nitrogen }\end{array}$ & $\begin{array}{l}\text { Temperature 10\% } \\
\text { mass loss }\left({ }^{\circ} \mathrm{C}\right)\end{array}$ & $\begin{array}{l}\text { Residual weight } \\
\text { at } 700^{\circ} \mathrm{C}(\%)\end{array}$ \\
\hline PEEK & $567 \pm 2$ & $582 \pm 4$ & $54.7 \pm 1.8$ \\
PEEK_25NdFeB & $555 \pm 2$ & $567 \pm 4$ & $71.1 \pm 1$ \\
PEEK_50NdFeB & $560 \pm 3$ & $576 \pm 2$ & $84.6 \pm 0.9$ \\
PEEK_75NdFeB & $559 \pm 1$ & - & $95.2 \pm 0.1$ \\
\hline
\end{tabular}


characteristic shape of the melt-spun powders, which are very irregular. The powder size distribution was found to be, in accordance to the datasheet, between 75 and $300 \mu \mathrm{m}$ measured by SEM analysis.

The XRD results Fig. 3 of the as received powder shows the presence of $\mathrm{Nd}_{2} \mathrm{Fe}_{14} \mathrm{~B}$. This phase is known $[52,53]$ to have the highest magnetic properties. The presence of soft magnetic phases, i.e. $\mathrm{Fe}$ and $\mathrm{Fe}_{3} \mathrm{~B}$, was also revealed from XRD analysis and might have an influence on the magnetic polarization saturation (and finally also the remanence) of the final produced materials.

From the TGA (Fig. 4) the mass gain shows a fairly sharp increase at approximately $580^{\circ} \mathrm{C}$, followed by a further increase at $620^{\circ} \mathrm{C}$ which sums up to around $11 \pm 2 \%$. This is in good agreement with similar data found in the literature [13]. This double peaked behavior can be attributed to the formation of various oxides while the oxidative attack proceeds from the $\mathrm{Nd}$-rich grain boundary phase through $\mathrm{Nd}_{2} \mathrm{Fe}_{14} \mathrm{~B}$ grains. It is expected, according to literature [52, 53], that the corrosion products are mostly oxides, such as $\mathrm{Fe}$ (II) (FeO) and $\mathrm{Fe}$ (III) $\left(\mathrm{Fe}_{2} \mathrm{O}_{3}\right), \mathrm{Nd}_{2} \mathrm{O}_{3}$ and $\alpha-\mathrm{Fe}_{2} \mathrm{O}_{3}$. However according to [4, 54], absorption are also expected due to the formation of other corrosion products, and their possible interaction with humidity.

According to TGA results, the powder can be considered stable against oxidation, both during filament preparation and FFF printing, as the processing temperature in both cases does not exceed $450^{\circ} \mathrm{C}$, which is well below $580^{\circ} \mathrm{C}$, above which TGA starts to record weight variation. Moreover, during the FFF printing, the magnetic filler is expected to be protected by the polymeric matrix.

In view of filament manufacturing through extrusion and successive FFF printing of the magnetic composites, the melt flow Index (MFI) was measured at $400{ }^{\circ} \mathrm{C}$. As it is well known from literature $[55,56]$ The MFI parameter is related to the viscosity of the material under test and the lower, the higher the viscosity of the polymer. Therefore, as it is possible to observe from the results reported in Table 2 reveal, the decrease of MFI at increasing filler amount can be associated to an increase of the viscosity (not measured). This could lead to some difficulties in the printing process.

\section{Filaments characterization}

Thermal characterization of extruded filaments was assessed by means of non-isothermal DSC analysis in nitrogen atmosphere, and the results are shown in Table 3 (error are within sensitivity of the instrument).
Table 6 Expected and measured density and weight percentages for all prepared filaments

\begin{tabular}{lllllll}
\hline & \multicolumn{2}{l}{$\begin{array}{l}\text { Nominal filler } \\
\text { content }\end{array}$} & $\begin{array}{l}\text { Nominal } \\
\text { density }\end{array}$ & Measured density & Porosity \\
\cline { 2 - 4 } & wt\% & vol\% & $\mathrm{g} / \mathrm{cm} 3$ & $\mathrm{~g} / \mathrm{cm} 3$ & {$[\%]$} \\
\hline PEEK_Neat & - & - & 1.300 & $1.294( \pm 0.025)$ & 0.5 \\
PEEK_25NdFeB & 25 & 5.37 & 1.633 & $1.623( \pm 0.038)$ & 0.6 \\
PEEK_50NdFeB & 50 & 14.56 & 2.212 & $2.172( \pm 0.021)$ & 1.8 \\
PEEK_75NdFeB & 75 & 33.82 & 3.427 & $2.935( \pm 0.039)$ & 14.3 \\
\hline
\end{tabular}

The second melting $\left(\mathrm{X}_{\mathrm{m}} \mathrm{II}\right)$ and cooling cycle $\left(\mathrm{X}_{\mathrm{c}}\right)$ evidenced the influence of filler on crystallinity, as it decreases with increasing filler content. This can be due to particles that may impede the development of the polymeric chains as an ordered structure. During the second heating, crystallinity maintains the same trend at increasing amounts of filler, but it is generally higher than in the first heating, where the thermal history of the material reveals that the cooling after the filament extrusion was probably too fast, thus not allowing the polymeric chains to form the crystal phase.

Results from DMTA analysis are reported in Fig. 5. The storage modulus at room temperature and the glass transition temperature (taken as the maximum of $\tan \delta$ curve from DMTA) of the composite filaments are higher than that of neat PEEK filaments (Table 4). Such effects have been observed in other polymer systems filled with finely dispersed materials [57]. The storage modulus (E'), in particular, evidences a marked increase above $50 \%$ wt loading.

TGA results (Table 5) indicate that the presence of the filler in the filaments changes the onset of thermal degradation with respect to the PEEK NEAT, which is most probably due to the thermal conductivity of the $\mathrm{NdFeB}$ particles. The residual mass of the PEEK NEAT filaments recorded at the end of the test (Table 5) can be related to the presence of a carbonaceous char as result of polymer decomposition. In PEEK degradation, as reported in the literature [58], the first decomposition step is associated to the scission of both ether bonds and

Table 7 Values of tensile strength, elastic modulus and elongation at break for all compositions ( $3 \sigma$ confidence intervals in brackets)

\begin{tabular}{llll}
\hline & Elastic modulus $(\mathrm{GPa})$ & $\begin{array}{l}\text { Tensile strength } \\
(\mathrm{Mpa})\end{array}$ & $\begin{array}{l}\text { Elongation at } \\
\text { break }(\%)\end{array}$ \\
\hline PEEK_neat & $3.0( \pm 0.2)$ & $89( \pm 5)$ & 52 \\
PEEK_25NdFeB & $3.2( \pm 0.2)$ & $80( \pm 5)$ & $5( \pm 2)$ \\
PEEK_50NdFeB & $4.2( \pm 0.5)$ & $75( \pm 3)$ & $4( \pm 1)$ \\
PEEK_75NdFeB & $4.3( \pm 0.8)$ & $51( \pm 8)$ & $2( \pm 1)$ \\
\hline
\end{tabular}



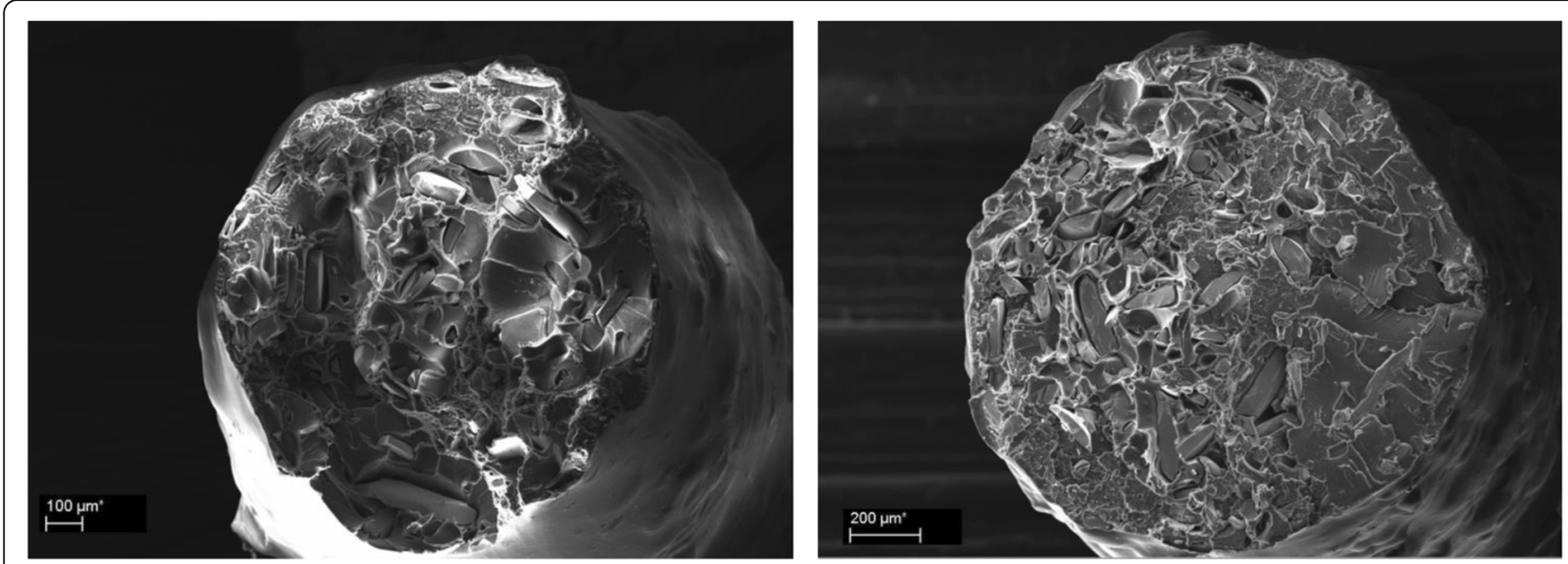

Fig. 6 Fracture surfaces of PEEK_25NdFeB (left) and PEEK_50NdFeB (right)

carbonyl bonds in the ketone group. The second step consists of a rapid and significant mass loss, which occurs just below $600^{\circ} \mathrm{C}$, resulting in the volatilization of around $45 \%$ of the polymer mass.

The residual mass of $\mathrm{NdFeB}$ filled samples was higher than that of the nominal filler content, due to the presence of the residual mass of PEEK. It can be concluded that TGA measurements cannot provide a reliable estimation of filler content in the filaments, and hence density measurements have been performed showing that the measured values are in agreement with the theoretical ones, calculated by the rule of mixture of Eq. 1. The estimated filler content in the filaments, as calculated from the density measurements (Table 6) was found to be slightly lower than expected, particularly in highly loaded samples. This is most probably due to the presence of porosity.
As the addition of filler is increased, the Modulus of elasticity (E) also shows an increase (Table 7). This is expected, as the filler is much stiffer than the polymeric matrix, particularly from 50\%wt, according to DMTA results. Consequently, the elongation at break decreases with increasing amount of particles, as the presence of the particles hinder the chain elongation in the direction of the applied load. Also, the interface between the particles and the matrix is not as strong as the intermolecular bonding in the matrix. Accordingly, the SEM micrographs (Fig. 6 and Fig. 7) of the fracture surfaces of the filaments after tensile tests evidenced some degree of ductility in PEEK $25 \mathrm{NdFeBsample}$, while the $50 \%$ loaded sample shows a more brittle fracture. Tensile strength decreases with increasing particle content. The particles do not act as a reinforcement to the matrix, mostly due to the limited adhesion to the matrix (SEM micrograph
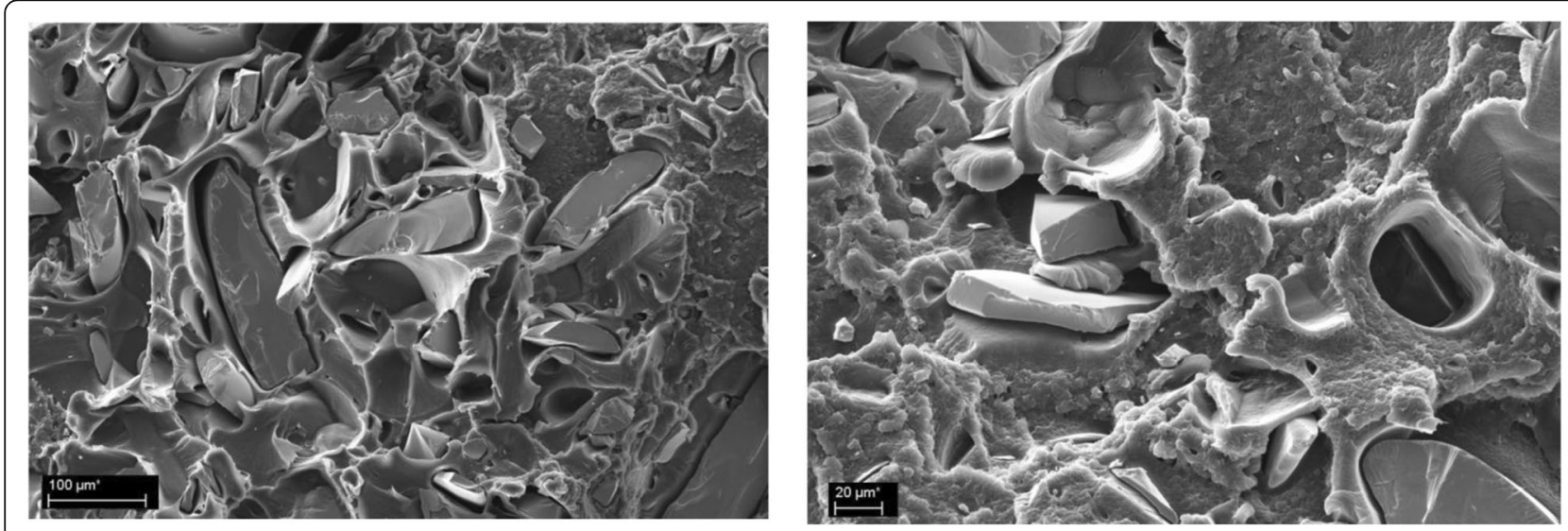

Fig. 7 Higher Magnification (150x) (left) and PEEK_50NdFeB (350x)(right) fracture surface details 

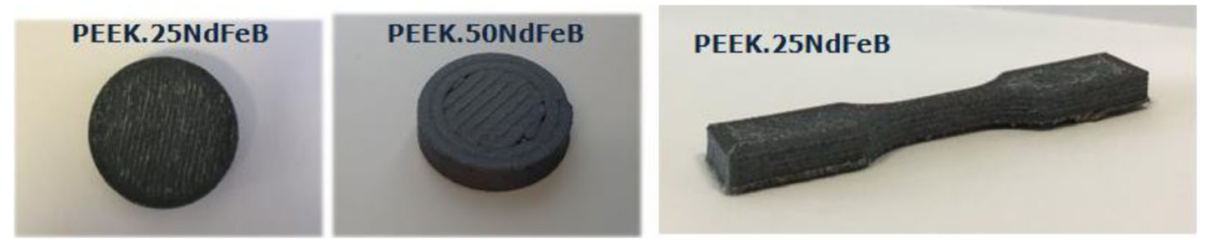

Fig. 8 3D printed samples: magnetic sample PEEK NdFeB 25 (left) magnetic sample PEEK NdFeB 50 (centre), tensile test sample PEEK NdFeB25

of Fig. 7) and to their micrometric dimension. The particles, in some cases, act as defects providing stress concentration around their sharp edges, where most of the cracks are originated (see Fig. 7). Additionally, debonding of the matrix from the particles results in the formation of voids, allowing more crack propagation (Fig. 7).
As discussed previously, a limited matrix/filler interfacial adhesion was observed in the SEM micrographs. Matrix/filler adhesion could be improved nevertheless, the use of coupling agents, that were proven to be effective in other systems (as silane [59-61], stearic acid [62] and polysulfones [63]) shall be assessed for these materials, due to the high temperature of the

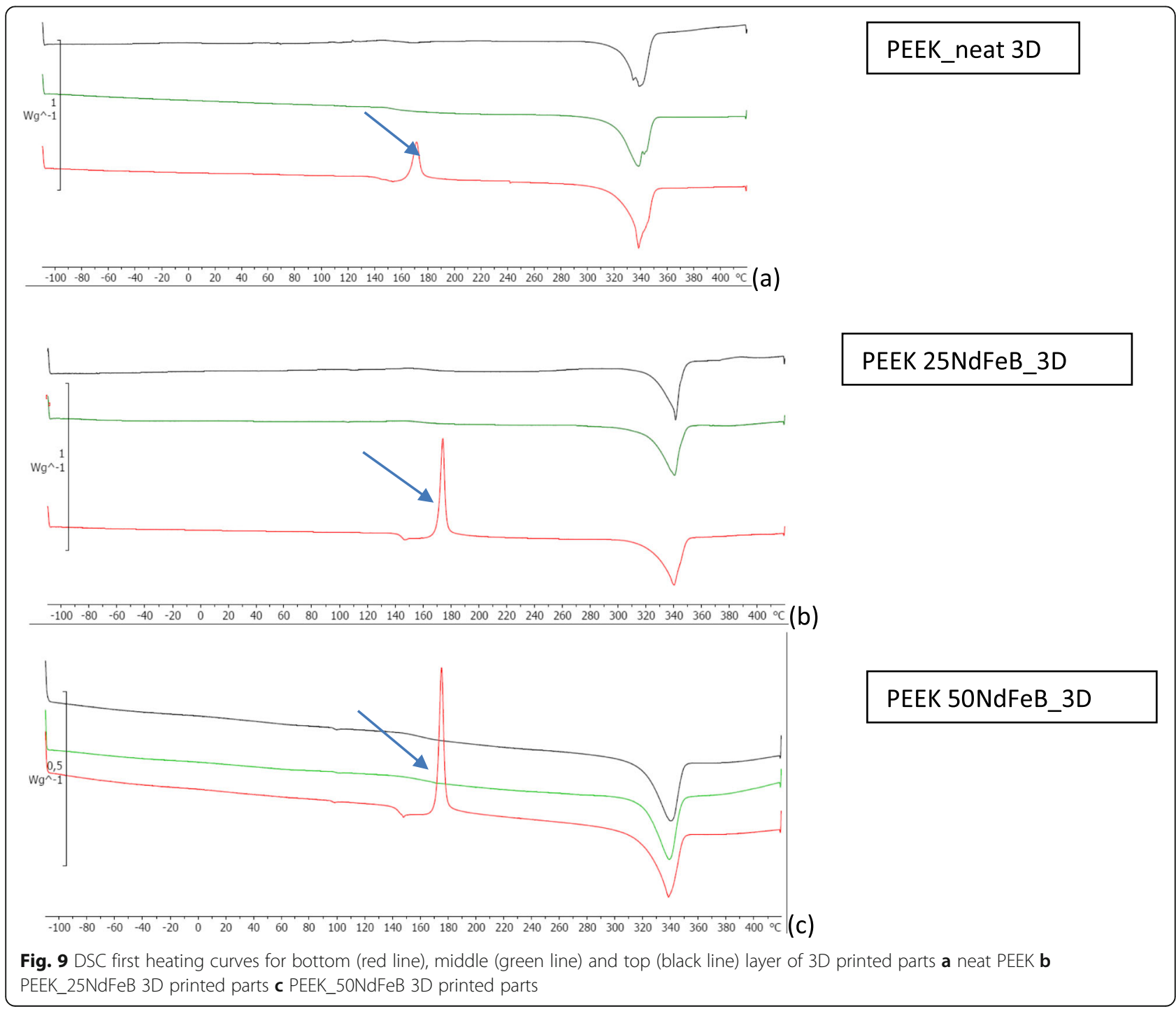



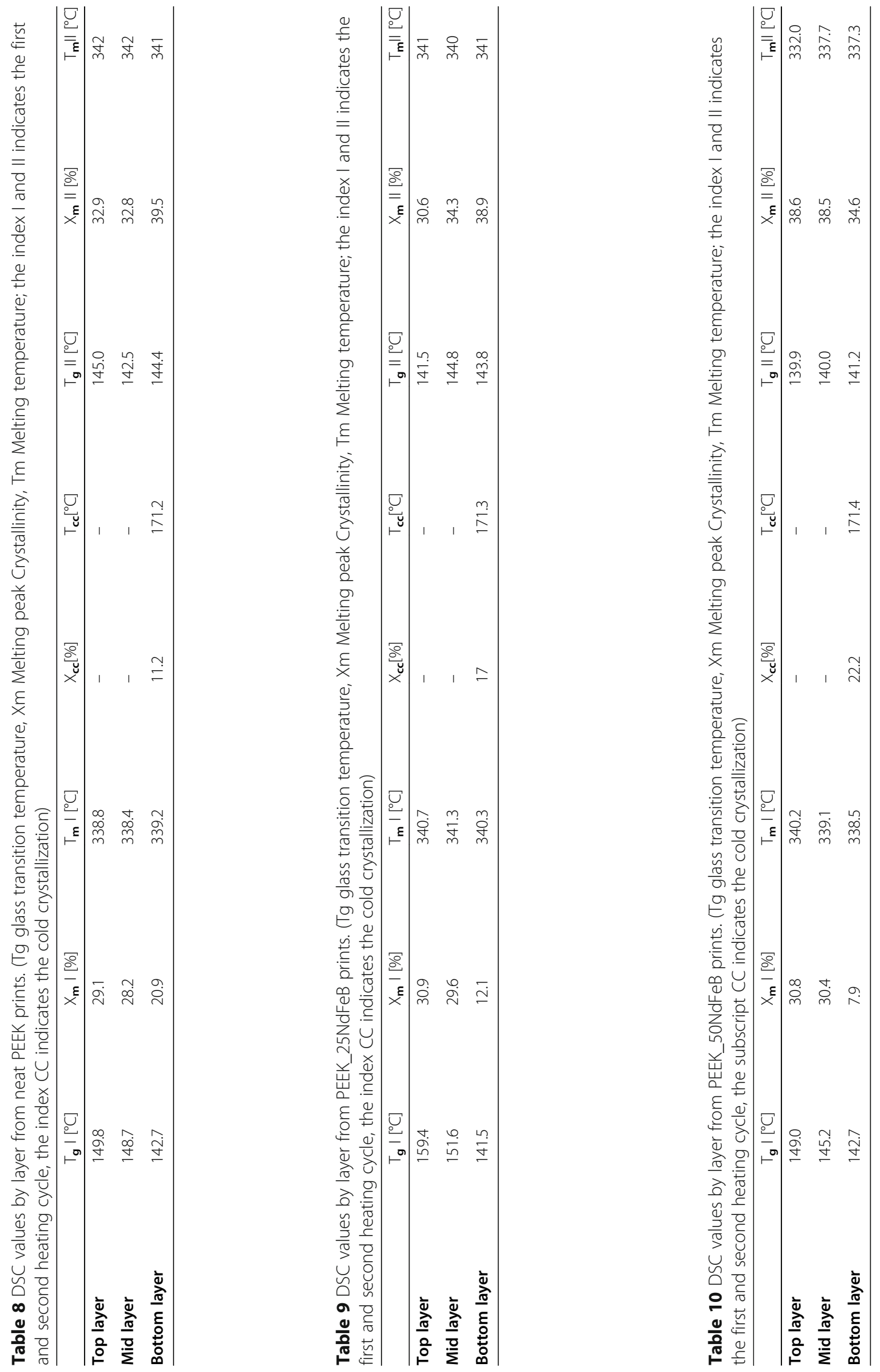


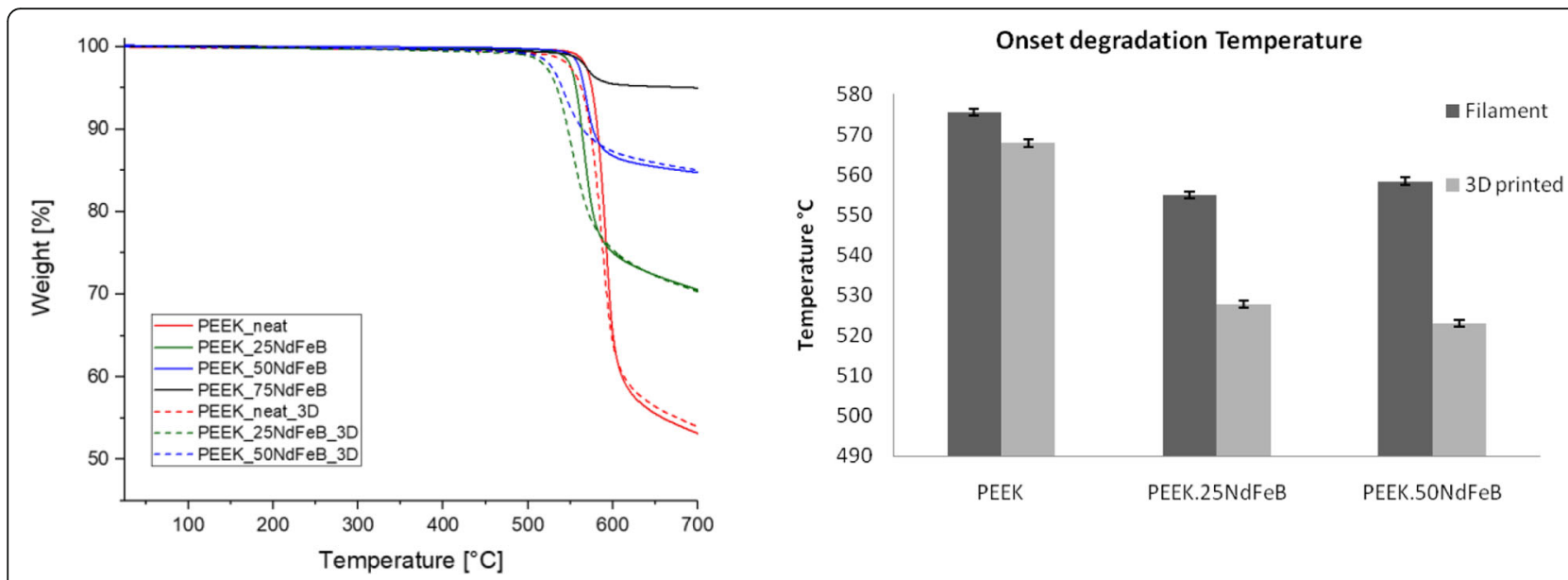

Fig. 10 TGA curves in Nitrogen for all PEEK NdFeB composites: continuous line are referred to filaments, dashed line are referred to 3D printed samples; right figure highlights the differences on the onset temperature

extrusion and printing process and to the high chemical reactivity of the metallic powders.

\section{Characterization of the 3D printed parts}

FFF printing of neat PEEK and PEEK_25NdFeB occurred without any issues, while the PEEK_50NdFeBfilaments required the use of a nozzle with a larger diameter of $0.8 \mathrm{~mm}$. This was expected, as its MFI was very low, indicating that the melt viscosity of the composite is high. Moreover, in this latter case, it was possible to print only the samples for the magnetic characterization, not the dogbone specimens (Fig. 8). At the present stage, the FFF printing of PEEK_75NdFeB_3D was not successful, as the filament were very stiff and practically no adhesion among the layers was achieved.

An extensive thermal characterization was performed on the 3D printed samples in order to assess the effects of the printing process on the material properties.

The DSC curves for all three layers are reported for: PEEK neat (Fig. 9a), PEEK_25NdFeB (Fig. 9b) and PEEK_50NdFeB (Fig. 9c), while the relevant values are reported respectively in Table 8, Table 9 and Table 10. In all cases, it is interesting to observe that the DSC curves of the bottom layer are different to those of the upper layers, as in the former case the presence of a distinct cold crystallization peak (blue arrows in Fig. 9a,b,c) was recorded, that is related to the presence of a non-equilibrium amorphous phase. This amorphous fraction is usually due to a rapid cooling that impedes the polymeric chains to allocate properly in the crystal structure. Rapid cooling, on the other hand, is related to the presence of a high thermal gradient between the nozzle and the plate. This leads to the conclusion that a higher temperature of the plate could be beneficial, allowing for a more suitable rate of polymer solidification. On the other hand, the limited crystallinity of the bottom layer turns into less shrinkage with beneficial effect on the adhesion to the building platform.

Moreover, the peaks of cold crystallization were found to be more pronounced in magnetic samples, with a consequence on crystallinity. In fact, the crystallinity of the first layer is as low as $21 \pm 1 \%$ for PEEK_neat, decreases to $12 \pm 1 \%$ for PEEK_25NdFeB and has its minimum of $8 \pm 0.5 \%$ for PEEK_50NdFeB samples. If compared to the other layers, the first layers show a lack of crystallinity of $28 \pm 1.5 \%, 60 \pm 1 \%$ and $75 \pm 2 \%$, respectively. This is most probably linked to the thermal conductivity of the composites, that is expected to increase with increasing filler amount, and which renders the heat conduction between the deposited filaments

Table 11 Expected values after apparent density measurement of the printed parts

\begin{tabular}{llll}
\hline & $\begin{array}{l}\text { Nominal density } \\
\left(\mathbf{g} / \mathrm{cm}^{3}\right)\end{array}$ & $\begin{array}{l}\text { Measured density } \\
\left(\mathbf{g} / \mathrm{cm}^{3}\right)\end{array}$ & $\begin{array}{l}\text { Void content } \\
(\mathbf{v o l \% )}\end{array}$ \\
\hline PEEK_Neat_3D & 1.294 & - & $1.38 \pm 0.005$ \\
PEEK_25NdFeB_3D & 1.633 & $1.76 \pm 0.010$ & 14.8 \\
PEEK_5ONdFeB_3D & 2.212 & 18.8 \\
\hline
\end{tabular}



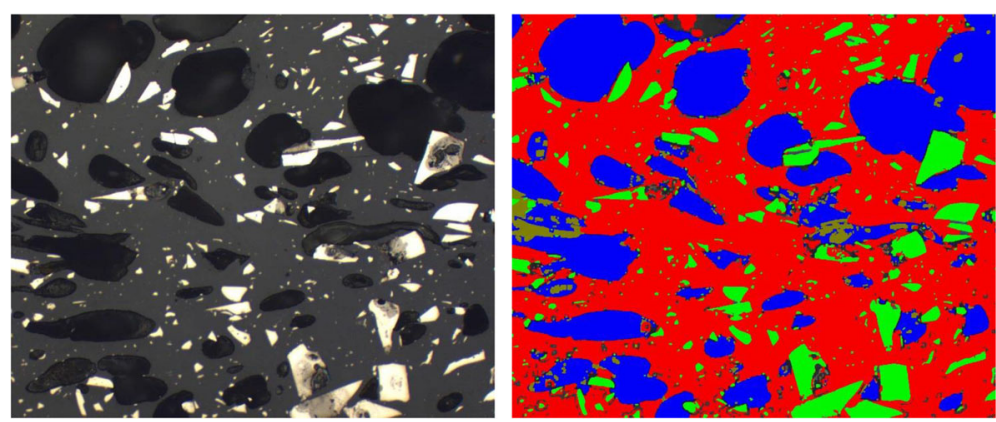

Fig. 11 Image (one of the 19) taken from at X 200 original magnification of the microsection of the PEEK_50NdFeB_3D (left) and result of the rieaboration with the Clemex Technologies Inc. software highlighting the presence of porosities (blue), PEEK matrix (red) and magnetic particles (green)

and the printing bed more efficient, promoting some quenching.

The results of thermogravimetric analysis (TGA) carried out on filaments and 3D printed samples are reported in Fig. 10 (left), while Fig. 10 (right) reports the values of onset degradation.

The onset of thermal degradation of all FFF printed samples appears at lower temperatures compared to the results of relative filaments, and as such, the effect becomes more evident with increasing filler content. This can be attributed to some degree to the degradation of the PEEK matrix during the printing, which is clearly accentuated by the presence of the filler. Literature reports [64] that at temperature as high as $400^{\circ} \mathrm{C}$ in air, PEEK can exhibit some degree of degradation and modifications such as crosslinking. In this regard, the cleavage of carbonyl or ether bonds can lead to the formation of relatively unstable radicals, which can combine between each other, leading to crosslinking and loss in terms of chains mobility [22, 30]. This phenomenon can occur during the printing as the filament sees a temperature of approximately $400^{\circ} \mathrm{C}$ as it passes through the nozzle.

The densities of the printed PEEK_25NdFeB and PEEK_ $50 \mathrm{NdFeB}$ were found to be $1.38 \mathrm{~g} / \mathrm{cm}^{3}$ and $1.76 \mathrm{~g} / \mathrm{cm}^{3}$ respectively. From such measurements, the void content of the printed parts was estimated, according to Eq. 1, as the different between the nominal expected density value and the measured one.

The results are reported in Table 11:

The amount of void content was confirmed by analysis of microsection (results reported only for PEEK_50NdFeB, Fig. 11), which revealed a presence of porosity of $20 \pm 1$ (average value among 19 measurements in different part of the sample) as reported in Fig. 12.

The results of the tensile tests of PEEK_neat_3D and PEEK_25NdFeB_3D printed samples are reported Table 12. The values of PEEK_neat are consistent with the scientific literature [39] and with those found for the filaments, highlighting the successful nature of the printing process. A general decrease in terms of mechanical properties, with respect to those of relevant filament, is evident for the $25 \%$ wt filled sample. This can be most probably attributed to a partial degradation occurring to the polymer during the printing. The analysis of the fracture surface of the 3D printed tensile test specimens after testing shows that good interlayer adhesion was achieved. However, in the case of PEEK_25NdFeB, a massive presence of voids

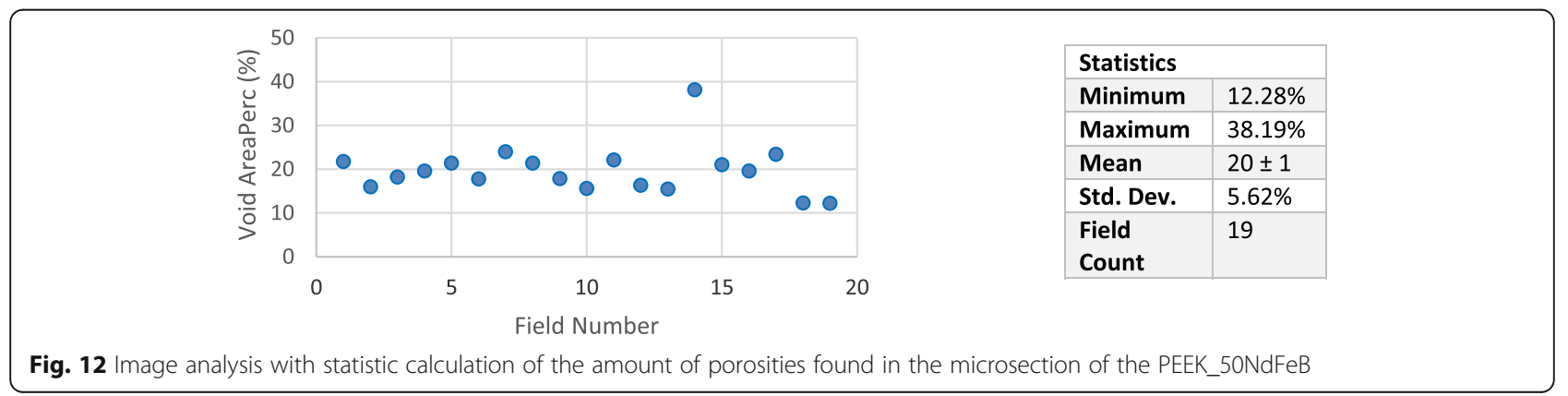


Table 12 Values of tensile strength, elastic modulus and elongation at break for neat PEEK and PEEK_25NdFeB 3D printed parts

\begin{tabular}{llll}
\hline & $\begin{array}{l}\text { Tensile strength } \\
(\mathrm{MPa})\end{array}$ & $\begin{array}{l}\text { Elastic modulus } \\
(\mathrm{GPa})\end{array}$ & $\begin{array}{l}\text { Elongation at } \\
\text { break (\%) }\end{array}$ \\
\hline PEEK_3D & $78( \pm 7)$ & $2.9( \pm 0.3)$ & $7( \pm 3)$ \\
PEEK__E3 & $60( \pm 9)$ & $2.5( \pm 0.6)$ & $4( \pm 1)$ \\
25NdFeB_3D & & & \\
\hline
\end{tabular}

in each layer, associated to the loss of magnetic filler, was observed (Fig. 13). This is due to the no optimal filler/ matrix adhesion, as already observed for the filament.

The magnetic properties of the FFF printed composite materials was assessed. As previously reported the as-received particles were mixed in vacuum with the polymeric matrix, extruded and printed in their non-magnetic state. After printing, the samples were magnetized at room temperature, results are reported in Table 13 and in Fig. 14 (hysteresis loops).

Both PEEK_25NdFeB and PEEK_50NdFeB have adequate magnetic properties, despite being slightly lower than the theoretical value. This difference could be explained considering that the 3D printed samples contain a not-negligible presence of porosity, as verified by density measures and microsection analysis. The voids, being non-magnetic, act against the effect of the filler. The expected $\mathrm{Br}$ has been calculated according to Eq. 3 and two different cases have been considered:

- Ideal case: based on the assumption that no voids present in the samples $\left(\mathrm{V}_{\text {void }}=0\right.$ in Eq. 3$)$. In this case, the discrepancy among the measured $\mathrm{Br}$ and
Table 13 Magnetic properties of the printed samples

\begin{tabular}{llll}
\hline & $\mathrm{Hcj}[\mathrm{kA} / \mathrm{m}]$ & $\mathrm{B}_{\mathrm{r}}[\mathrm{mT}]$ & $(\mathrm{BH})_{\max }\left[\mathrm{J} / \mathrm{m}^{3}\right]$ \\
\hline PEEK_25NdFeB_3D & $413( \pm 18)$ & $26( \pm 2)$ & $130( \pm 4)$ \\
PEEK_50NdFeB_3D & $167( \pm 10)$ & $69( \pm 5)$ & $750( \pm 13)$
\end{tabular}

the $\mathrm{Br}$ expected might be related to different issues: the amount of filler in the composite is lower than the nominal filler content, some degradation of the magnetic powders might have occurred or the magnetic properties declared in the datasheet are lower with respect to the real values. The results for the ideal case are reported in Table 14

- Real case: voids present in the samples are taken into account (according to the values calculated with standard methods, results reported in Table 11). In this case the discrepancy among the measured $\mathrm{Br}$ and the $\mathrm{Br}$ expected is due to the presence of porosities in the sample. The results are reported in Table 15

The relative magnetic performance loss appears to be much lower in the real case (when porosities are taken into account) with respected to the ideal case (no voids considered in the calculation). This is due to the fact that in the first case, not taking into account the presence of porosities the discrepancy among the measured $B_{r}$ and the expected values is quite high. The difference among the $\mathrm{Br}$ loss in the ideal and real case suggested that the loss in magnetic properties could be also related to some other degradation phenomena, other than the presence of voids, that might have occurred during the processing.
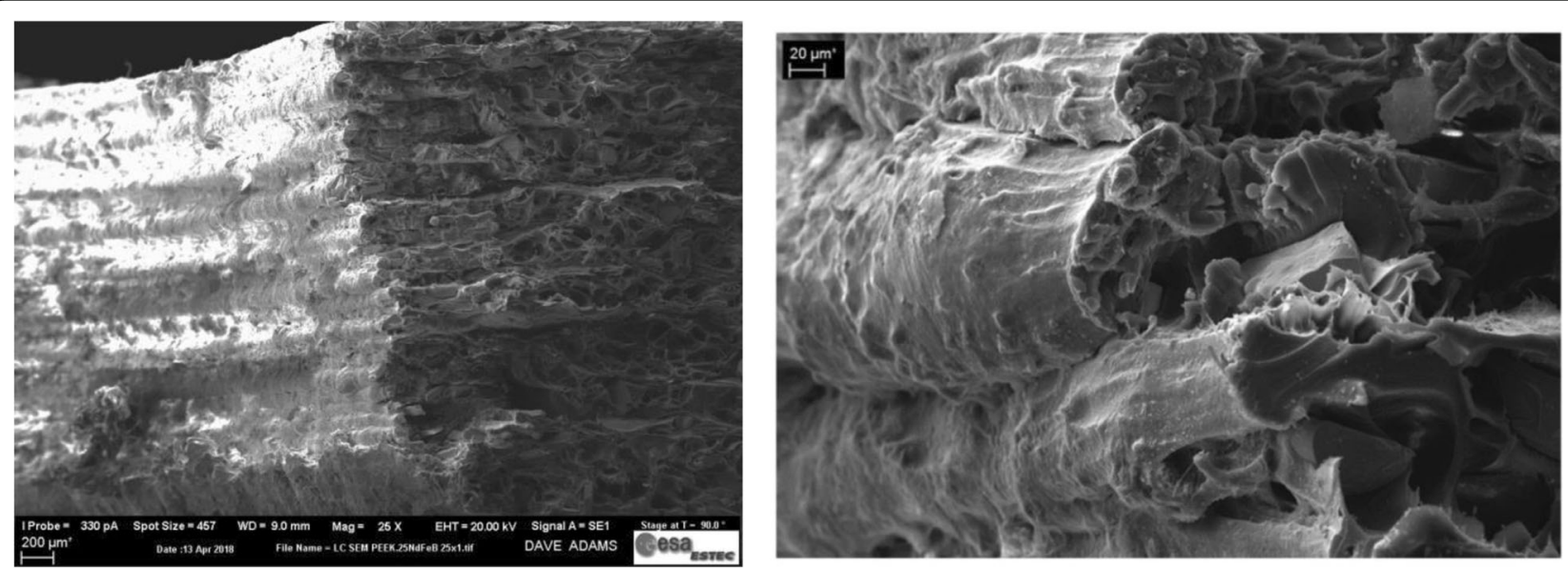

Fig. 13 3D printed PEEK_25NdFeB (right) surface fracture after tensile testing. Detail of layer adhesion 

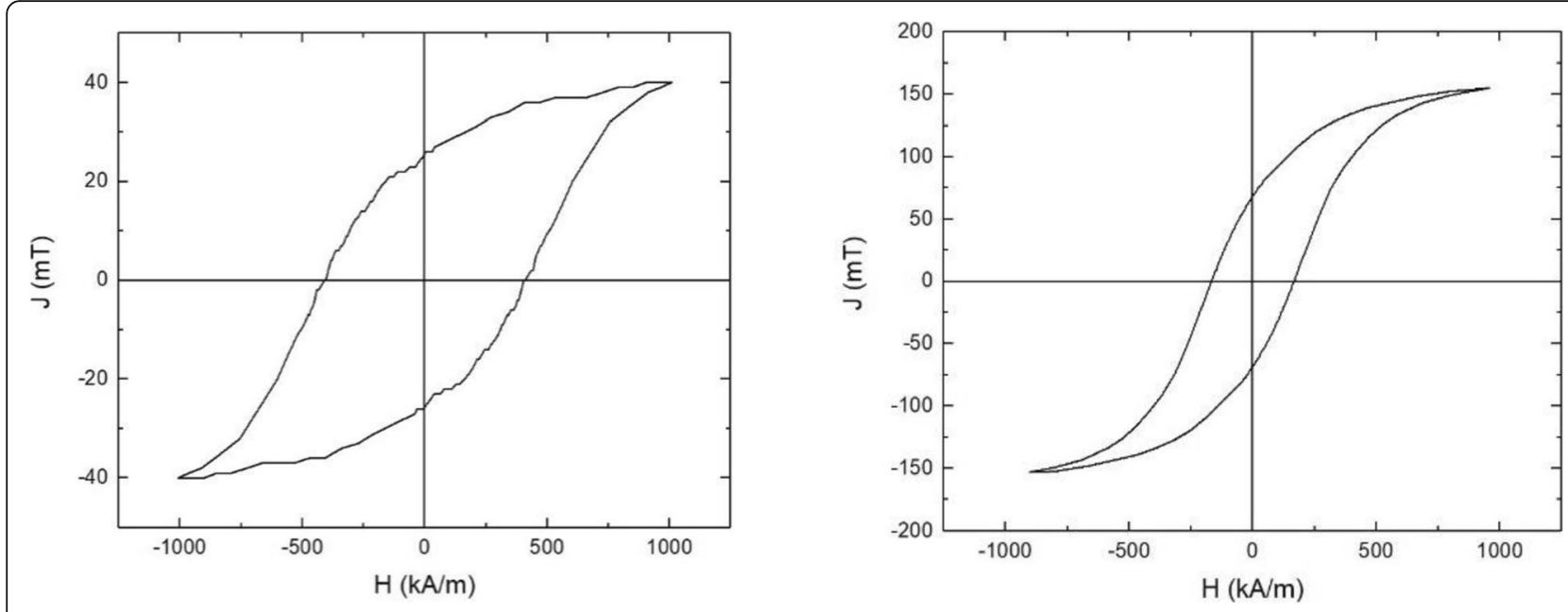

Fig. 14 Hysteresis loop for PEEK_25NdFeB printed magnet (left) and PEEK_50NdFeB printed magnet (right)

The possibility of a loss in $B_{r}$ due to some degree of oxidation of the magnetic phase $\mathrm{Nd}_{2} \mathrm{Fe}_{14} \mathrm{~B}$ during processing might be a possible explanation of the large discrepancy among the expected remanence value and the measured one. The phase $\mathrm{Nd}_{2} \mathrm{Fe}_{14} \mathrm{~B}$ exhibits the highest ferromagnetic properties in the material, while the oxidation products (mostly $\mathrm{Nd}$ and Fe Oxide) are not proving a contribution in terms of magnetic properties [5].

Despite the characterization of the as received powder did not reveal the presence of oxidation (XRD results), and the thermal stability was judged high enough to prevent degradation during the printing process (TGA results on as received metallic powder), EDX map analysis Fig. 15 have been performed on the particles contained in printed samples revealing some degree of oxidation. At the particles surface and on the internal areas the $\mathrm{Nd}$ and $\mathrm{Fe}$ content was found to be low and the oxygen content high, suggesting the formation of species coming from oxidation reaction, that might have occurred among $\mathrm{Nd}$ and $\mathrm{O}$ and Fe and O. Such results can explain the reduction of the magnetic properties found in printed parts for both PEEK_50NdFeB and PEEK_25NdFeB.

Finally, coercitivity was found to be much lower in PEEK_50NdFeB printed parts with respect to PEEK_

Table 14 Expected values after apparent density measurement of the 3D_PEEK_NdFeBsamples (ideal case)

\begin{tabular}{|c|c|c|c|c|}
\hline & \multirow{2}{*}{$\begin{array}{l}\text { Measured } \\
\mathrm{Br}[\mathrm{mT}]\end{array}$} & \multirow{2}{*}{$\begin{array}{l}\text { Nominal Filler } \\
\text { content } \\
\text { vol [\%] }\end{array}$} & \multicolumn{2}{|c|}{$\begin{array}{l}\text { Magnetic } \\
\text { properties } \\
\text { (without voids) }\end{array}$} \\
\hline & & & $\mathrm{Br}_{\text {exp }}[\mathrm{mT}]$ & Br loss $[\%]$ \\
\hline 3D_PEEK_25NdFeB & $26 \pm 1.5$ & 5.37 & 39.74 & 34.57 \\
\hline 3D_PEEK_50NdFeB & $69 \pm 1.5$ & 14.56 & 116.48 & 40.76 \\
\hline
\end{tabular}

$25 \mathrm{NdFeB}$ samples that, instead, confirmed the value of coercitivity expected for the powders (roughly 440 $\mathrm{kA} / \mathrm{m}$ according to the supplier datasheet). Coercitivity, though, is not affected by the porosity of the samples, as it is an intrinsic property of the materials [22, 65]. Therefore, it is believed that a possible explanation for such finding has to be addressed to a different degree of filler orientation in the printing direction that is quite high in the case of PEEK $25 \mathrm{NdFeB}$, and much more limited in the case of PEEK_50NdFeB, as the massive presence of filler amount forced the use of a larger nozzle.

\section{Conclusions}

PEEK-NdFeB composite filaments were produced by means of a single-screw extruder equipped with a mixing head to ensure good mixing between particles and matrix. The effect of filler quantity was assessed in terms of mechanical and thermal properties. The printing activity was performed to enable the mechanical and magnetic properties to be evaluated.

DSC analysis on the printed parts was performed to evaluate the quality of the print. The first layer was found to have a lower degree of crystallinity, reported by the presence of a cold crystallization peak after the glass transition. When compared to that of the upper layers,

Table 15 Comparison between measured $\mathrm{Br}$ and expected values for the 3D_PEEK_NdFeB samples taking into account the presence of voids (real case)

\begin{tabular}{llllll}
\hline & Measured & $\begin{array}{l}\text { Nominal } \\
\text { Filler content }\end{array}$ & Porosities & $\begin{array}{l}\text { Magnetic } \\
\text { properties } \\
\text { (with voids) }\end{array}$ \\
& $\mathrm{Br}[\mathrm{mT}]$ & $\mathrm{vol}[\%]$ & {$[\%]$} & $\mathrm{Br}_{\exp }[\mathrm{mT}]$ & $\mathrm{Br}$ loss [\%] \\
\hline 3D_PEEK_25NdFeB & $26 \pm 1.5$ & 5.37 & 14.80 & 33.86 & 23.21 \\
3D_PEEK_50NdFeB & $69 \pm 1.5$ & 14.56 & 18.80 & 94.58 & 27.05 \\
\hline
\end{tabular}



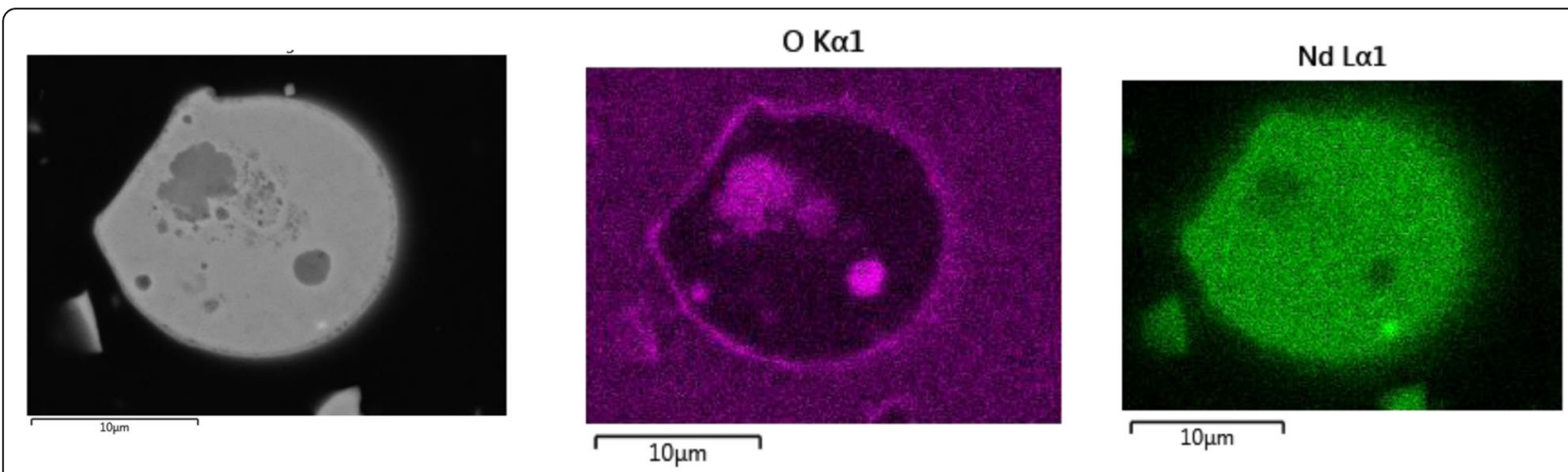

Ni $K \alpha 1$

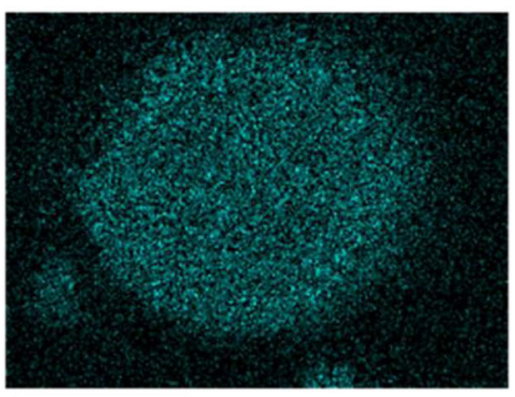

$10 \mu \mathrm{m}$

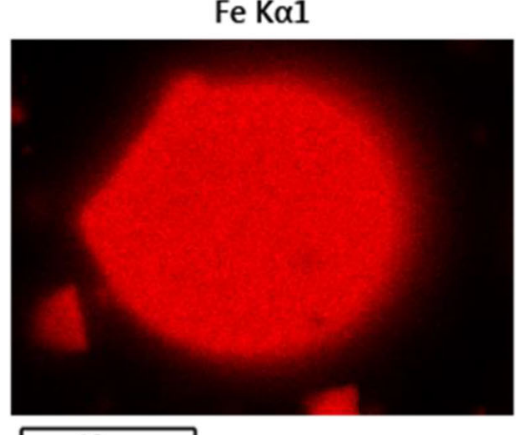

$10 \mu \mathrm{m}$

Fig. 15 Map analysis performed by EDX of the magnetic particle on the PEEK_50NdFEB composite

the first showed a lack of crystallinity of roughly 10, 18 and $22 \%$ for the increasing filler content. This is linked to the higher thermal gradient occurring when printing the first layers that are in direct contact with the cooler plate. Moreover, TGA analysis of the prints in comparison to the relevant filaments shows a loss in thermal stability after printing.

Tensile testing of the 3D composite printed parts showed a lower tensile strength with respect to PEEK neat value. This was due to the lack of an efficient interface between the matrix and the particles, and to the fact that the particles contained many irregular edges that act as initiation sites for cracks.

Finally, magnetic measurement shows energy products of $130 \mathrm{~J} / \mathrm{m}^{3}$ for PEEK_25NdFeB and $750 \mathrm{~J} / \mathrm{m}^{3}$ for PEEK_ $50 \mathrm{NdFeB}$ demonstrating the feasibility of the magnetic $3 \mathrm{D}$ printed composite with PEEK. These values are slightly lower than the optimal ones $(25 \%$ and $33 \%$, respectively), but encouragingly, the results are consistent with what was found in the literature for PA-based additively manufactured bonded magnets. The presence of a not negligible amount porosity and, in the case of PEEK_50NdFeB sample, the lack of filler orientation were considered the major findings. Therefore, further optimization of the printing process is required to develop a magnet that will have the optimum performance for use in space applications.

\section{Abbreviations}

PEEK: Poly ether ether ketone; ALM: Additive layer manufacturing; FDM: Fused deposition modeling; PM: Permanent magnets; FFF: Fused filamentfabrication; MFI: Melt flow index; DSC: Differential scanning calorimetry; XRD: X Ray diffraction; TGA: ThermoGravimetric analysis; Tg: Glass transition temperature; Tm: Melting temperature; Xm: Melting peak crystallinity; CC: Cold crystallization

\section{Acknowledgements}

The SEM analysis were performed at ESA ESTEC Laboratories, by Dave Adams. The authors would also like to express the sincere gratitude to Fabio Franceschetti for his effort for the success of the project.

\section{Authors' contributions}

L. Pigliaru and M. Rinaldi conceived the topic; L. Pigliaru and F. Nanni drafted the article; L. Pigliaru, M. Rinaldi, L. Ciccacci conducted the experiments and analized the data; A. Norman, T. Rohr, T. Ghidini, F. Nanni reviewed and corrected the article. The authors read and approved the final mnuscript.

Funding

This research did not receive any specific grant from funding agencies in the public, commercial, or not-for-profit sectors.

Availability of data and materials

All data generated or analysed during this study are included in this published article.

Ethics approval and consent to participate Not applicable.

Consent for publication

Not applicable.

Competing interests

The authors declare that they have no competing interests. 


\section{Author details}

'Structure, Mechanism and MaterialsDivision, European Space Agency, NL-2200, AG, Noordwijk, The Netherlands. ${ }^{2}$ Italian Interuniversity Consortium on Materials Science and Technology (INSTM), Research Unit Roma Tor Vergata, Via della Ricerca Scientifica, 00133 Rome, Italy. ${ }^{3}$ Department of Enterprise Engineering, University of Rome Tor Vergata, Via del Politecnico, 00133 Rome, Italy.

\section{Received: 23 December 2019 Accepted: 18 March 2020 Published online: 19 May 2020}

\section{References}

1. S. Nishio, S. Sugimoto, R. Goto, M. Matsuura, N. Tezuka, Mater. Trans. 50, 723 (2009)

2. A.A. El-Moneim, A. Gebert, M. Uhlemann, O. Gutfleisch, L. Schultz, Corros. Sci. 44, 1857 (2002)

3. W. Rodewald, B. Wall, and W. Fernengel, "Grain Growth Kinetics in Sintered Nd-Fe-B Magnets," IEEE Trans. Magn., 33, 5 (1997)

4. A. S. Kim, F. E. Camp, and S. Constantinides, "Corrosion Mechanism of NdFe-B Magnets in Humid Environments"

5. M. Katter, L. Zapf, R. Blank, W. Fernengel, and W. Rodewald, "Corrosion mechanism of RE-Fe-Co-Cu-Ga-Al-B magnets," in IEEE Transactions on Magnetics, (2001), https://doi.org/10.1109/20.951207

6. A. Saliba-Silva, R.N. Faria, M.A. Baker, I. Costa, Surf. Coat. Technol. 185, 321 (2004)

7. J. Fidler, T. Schrefl, "Overview of $\mathrm{Nd}-\mathrm{Fe}-\mathrm{B}$ magnets and coercivity (invited) Symposium on High Performance Permanent Magnets and Coercivity George Hadjipanayis, Chairman Overview of $\mathrm{Nd}-\mathrm{Fe}-\mathrm{B}$ magnets and coercivity (invited)," vol. 5029, no. May 2014, pp. 1-7, (1996) https://doi.org/10.1063/1.361565

8. A.Z. Liu, I.Z. Rahman, M.A. Rahman, E.R. Petty, J. Mater. Process. Technol. $\mathbf{5 6}$ 571 (1996)

9. J. Xiao, J.U. Otaigbe, Polym. Compos. 21, 332 (2000)

10. L. Pigliaru, M. Rinaldi, L. Ciccacci, A. Allegranza, T. Rohr, T. Ghidini, F. Nanni, Conf. Pap. Proc. 69th Int. Astronaut. Congr. (Ref. Oral IAC-18,C2,8,7,X48291) (Bremen, 2018)

11. J. J. Croat, J. F. Herbst, R. W. Lee, and F. E. Pinkerton, "Pr-Fe and Nd-Fe-based materials: A new class of high-performance permanent magnets (invited)," J. Appl. Phys., (1984) https://doi.org/10.1063/1.333571

12. M. Sagawa, S. Fujimura, N. Togawa, H. Yamamoto, and Y. Matsuura, "New material for permanent magnets on a base of $\mathrm{Nd}$ and Fe (invited)," J. Appl. Phys., (1984) https://doi.org/10.1063/1.333572

13. M. Kokabi, F. Arabgol, M. Manteghian, Nd2Fe14B permanent polymeric composite magnets, Iran. Polym. J. (English Ed. (2005)

14. L. Li, A. Tirado, I.C. Nlebedim, O. Rios, B. Post, V. Kunc, R.R. Lowden, E. LaraCurzio, R. Fredette, J. Ormerod, T.A. Lograsso, M.P. Paranthaman, Sci. Rep. 6, 1 (2016)

15. C. Huber et al., "3D Printing of Polymer-Bonded Rare-Earth Magnets with a Variable Magnetic Compound Fraction for a Predefined Stray Field," Sci. Rep. (2017) https://doi.org/10.1038/s41598-017-09864-0

16. M.G. Garrell, B.M. Ma, A.J. Shih, E. Lara-Curzio, R.O. Scattergood, Mater. Sci. Eng. A 359, 375 (2003)

17. I. Gibson, D.W. Rosen, B. Stucker, Additive Manufacturing Technologies: Rapid Prototyping to Direct Digital Manufacturing (2010)

18. F. Cecchini, V. Cherubini, M. Rinaldi, F. Fabbrocino, F. Nanni, ICCE-25 Rome, July 16-22, 2017 Rome, Italy (Rome, 2017)

19. T. Ghidini, Nat. Mater. (2018)

20. I. Cacciotti, M. Rinaldi, J. Fabbrizi, F. Nanni, J. Mater, Res Technol (2019)

21. L. Li, B. Post, V. Kunc, A. M. Elliott, and M. P. Paranthaman, "Additive manufacturing of near-net-shape bonded magnets: Prospects and challenges," Scr. Mater. (2017) https://doi.org/10.1016/.scriptamat.2016.12.035

22. L. Li et al., "Big Area Additive Manufacturing of High Performance Bonded NdFeB Magnets," Sci. Rep. (2016) https://doi.org/10.1038/srep36212

23. K. von Petersdorff-Campen et al., "3D Printing of Functional Assemblies with Integrated Polymer-Bonded Magnets Demonstrated with a Prototype of a Rotary Blood Pump," Appl. Sci., vol. 8, no. 8, (2018) https://doi.org/10.3390/ app8081275

24. J. Jacimovic et al., "Net Shape 3D Printed NdFeB Permanent Magnet," Adv. Eng. Mater. (2017) https://doi.org/10.1002/adem.201700098

25. B.G. Compton, et al., Direct-write 3D printing of NdFeB bonded magnets. Mater. Manuf. Process. 33.1, 109-113 (2018). https://doi.org/10.1080/ 10426914.2016.1221097
26. J. He, T. Lin, H. Shao, L. Zhao, D. Zhao, 3d printing of ndfeb rare earth permanent magnet. Xiyou Jinshu/Chinese J. Rare Metals. 42(6), 657-662 (2018). https://doi.org/10.13373/j.cnki.cjrm.XY17050013

27. A.P. Taylor, C. Velez Cuervo, D.P. Arnold, L.F. Velasquez-Garcia, Fully 3DPrinted, Monolithic, Mini Magnetic Actuators for Low-Cost, Compact Systems. J. Microelectromech. Syst. 28.3, 481-493 (2019). https://doi.org/10. 1109/JMEMS.2019.2910215

28. M. Skalon, M. Görtler, B. Meier, S. Arneitz, N. Urban, S. Mitsche, C. Huber, J. Franke, C. Sommitsch, Materials (Basel) (2020)

29. L. Pigliaru, M. Rinaldi, L. Cicacci, L. Paleari, M. Bragaglia, A. Norman, T. Rohr, T. Ghidini, F. Nanni, Proc. Int. Astronaut. Congr. IAC (2019)

30. K. Gandha, L. Li, I.C. Nlebedim, B.K. Post, V. Kunc, B.C. Sales, J. Bell, M.P. Paranthaman, J. Magn. Magn. Mater. 467, 8 (2018)

31. L. Li et al., "Fabrication of highly dense isotropic Nd-Fe-B nylon bonded magnets via extrusion-based additive manufacturing," Addit. Manuf. (2018) https://doi.org/10.1016/j.addma.2018.04.001

32. E. M. Palmero et al., "Magnetic-Polymer Composites for Bonding and 3D Printing of Permanent Magnets," IEEE Transactions on Magnetics, (2018)

33. S. M. Kurtz and J. N. Devine, "PEEK biomaterials in trauma, orthopedic, and spinal implants," Biomaterials. 2007, https://doi.org/10.1016/j.biomaterials. 2007.07.013.

34. S.M. Kurtz, J.N. Devine, Biomaterials (2007)

35. J. G. Funk, "The Effects of Simulated Space Environmental Parameters on Six Commercially Available Composite Materials," Langley Research Center, Hampton, Virginia (1989)

36. Y. Lee, R.S. Porter, Macromolecules 21, 2770 (1988)

37. D.J. Blundell, B.N. Osborn, Polymer (Guildf) 24, 953 (1983)

38. A. Jonas, R. Legras, Polymer (Guildf) 32, 2691 (1991)

39. M. Rinaldi, D. Puglia, F. Dominici, V. Cherubini, L. Torre, and F. Nanni, "Melt processing and mechanical property characterization of high performance poly(ether ether ketone)-carbon nanotube composite:" https://doi.org/10. 1002/pi.5451

40. L. Jin, J. Ball, T. Bremner, H.-J. Sue, Polymer (Guildf) 55, 5255 (2014)

41. M. Rinaldi, T. Ghidini, F. Cecchini, A. Brandao, F. Nanni, Compos. Part B Eng. 145, 162 (2018)

42. M. Vaezi, S. Yang, Virtual Phys Prototyp 10, 123 (2015)

43. B. Valentan, Ž. Kadivnik, T. Brajlih, A. Anderson, I. Drstvenšek, Mater Tehnol $47,715(2013)$

44. C. Yang, X. Tian, D. Li, Y. Cao, F. Zhao, C. Shi, J. Mater. Process. Technol. 248, 1 (2017)

45. B. J. Holland and J. N. Hay, "Thermal degradation of nylon polymers," Polym. Int. (2000) https://doi.org/10.1002/1097-0126(200009)49:9<943::AID-PI400>3. $0 . \mathrm{CO} ; 2-5$

46. "Melt Spun NdFeB Permanent Magnetic Powder." [Online]. Available: https:// newlandmagnetics.eu/quenched-powder/melt-spun-ndfeb-permanentmagnetic-powder/. (datasheet)

47. D.J. Blundell, B.N. Osborn, Polymer (Guildf) (1983)

48. A. Jonas, R. Legras, J.P. Issi, Polymer (Guildf) 32, 3364 (1991)

49. J.M.D. Coey, Magnetism and Magnetic Materials (2010)

50. X.H. Zhang, W.H. Xiong, Y.F. Li, N. Song, Mater. Des. 30, 1386 (2009)

51. D. Goll, H. Kronmüller, Naturwissenschaften (2000)

52. T. Žák, N. Talijan, V. Æosoviæ, and A. Grujiæ, "NdFeB permanent magnets with various Nd content," Acta Phys. Pol. A, vol. 113, no. 1, pp. 279-282, (2008) https://doi.org/10.12693/APhysPolA.113.279

53. T. Žák, N. Talijan, V. Ėosoviæ, and A. Grujiæ, "Structure and phases of lowneodymium NdFeB permanent magnets," Czechoslov. J. Phys., (2006) https://doi.org/10.1007/s10582-006-0470-2

54. M.J. McNallan, D.F. Cygan, Corrosion of NdFeB permanent magnets in humid environments at temperatures up to $150 \mathrm{deg}$ C. J. Magn, Magn Mater. 139.1, 131-138 (1995). https://doi.org/10.1016/0304-8853(95)90037-3

55. A.V. Shenoy, D.R. Saini, V.M. Nadkarni, Rheograms for engineering thermoplastics from melt flow index. Rheol. Acta. 22, 209-222 (1983). https://doi.org/10.1007/BF01332373

56. D. R. Saini and A. V. Shenoy, Melt Rheology of Some Specialty Polymers. J. Elastomers Plast. (1985). https://doi.org/10.1177/009524438501700305

57. S. Dul, L. Fambri, A. Pegoretti, Filaments production and fused deposition modelling of ABS/carbon nanotubes composites. Nanomaterials 8.1, 49 (2018). https://doi.org/10.3390/nano8010049

58. P. Patel, T.R. Hull, R.W. McCabe, D. Flath, J. Grasmeder, M. Percy, Polym. Degrad. Stab. 95, 709 (2010) 
59. M. Watanabe and T. Tamai, "Acrylic polymer/silica organic-inorganic hybrid emulsions for coating materials: Role of the silane coupling agent," J. Polym. Sci. Part A Polym. Chem. (2006) https://doi.org/10.1002/pola.21574

60. H. Taguchi, "High performance ferrite magnets - From the perspective of powder technology," KONA Powder and Particle Journal. (1998) https://doi. org/10.14356/kona.1998014

61. H. Chen, J. Zheng, L. Qiao, Y. Ying, L. Jiang, and S. Che, "Surface modification of NdFe12Nx magnetic powder using silane coupling agent KH550," Adv. Powder Technol. (2015) https:/doi.org/10.1016/j.apt.2015.01.011

62. J. Njuguna, K. Pielichowski, and S. Desai, "Nanofiller-reinforced polymer nanocomposites," Polym. Adv. Technol. (2008) https://doi.org/10.1002/pat.1074

63. A. M. Díez-Pascual, M. Naffakh, J. M. González-Domínguez, A. Ansón, Y. Martínez-Rubi, M. T. Martínez, B. Simard, and M. A. Gómez, Carbon N. Y. 48, $3485(2010)$

64. N. L. Buelow, "Microstructural investigation of mixed rare earth iron boron processed via melt-spinning and high-pressure gas-atomization for isotropic bonded permanent magnets.", Master of Science, lowa STate University

65. C. Huber, C. Abert, F. Bruckner, C. Pfaff, J. Kriwet, M. Groenefeld, I. Teliban, C. Vogler, D. Suess, J. Appl. Phys. (2017)

\section{Publisher's Note}

Springer Nature remains neutral with regard to jurisdictional claims in published maps and institutional affiliations.

\section{Submit your manuscript to a SpringerOpen ${ }^{\circ}$ journal and benefit from:}

- Convenient online submission

- Rigorous peer review

- Open access: articles freely available online

- High visibility within the field

- Retaining the copyright to your article

Submit your next manuscript at $\boldsymbol{\nabla}$ springeropen.com 